\title{
Fork Off! \\ The North American Governance of Obesity
}

\author{
By \\ Elizabeth R. McGuire
}

A thesis submitted to the Faculty of Graduate Studies and Research in partial fulfillment of the requirement for the degree of

\author{
Masters of Arts \\ Department of Law \\ Carleton University \\ January 192010
}


Library and Archives

Canada

Published Heritage Branch

395 Wellington Street

Ottawa ON K1A ON4

Canada
Bibliothèque et

Archives Canada

Direction du

Patrimoine de l'édition

395 , rue Wellington

Ottawa ON K1A ON4

Canada
Your file Votre rëférence

ISBN: 978-0-494-68684-3

Our file Notre référence

ISBN: 978-0-494-68684-3
NOTICE:

The author has granted a nonexclusive license allowing Library and Archives Canada to reproduce, publish, archive, preserve, conserve, communicate to the public by telecommunication or on the Internet, loan, distribute and sell theses worldwide, for commercial or noncommercial purposes, in microform, paper, electronic and/or any other formats.

The author retains copyright ownership and moral rights in this thesis. Neither the thesis nor substantial extracts from it may be printed or otherwise reproduced without the author's permission.
AVIS:

L'auteur a accordé une licence non exclusive permettant à la Bibliothèque et Archives Canada de reproduire, publier, archiver, sauvegarder, conserver, transmettre au public par télécommunication ou par l'Internet, prêter, distribuer et vendre des thèses partout dans le monde, à des fins commerciales ou autres, sur support microforme, papier, électronique et/ou autres formats.

L'auteur conserve la propriété du droit d'auteur et des droits moraux qui protège cette thèse. $\mathrm{Ni}$ la thèse ni des extraits substantiels de celle-ci ne doivent être imprimés ou autrement reproduits sans son autorisation.
In compliance with the Canadian Privacy Act some supporting forms may have been removed from this thesis.

While these forms may be included in the document page count, their removal does not represent any loss of content from the thesis.
Conformément à la loi canadienne sur la protection de la vie privée, quelques formulaires secondaires ont été enlevés de cette thèse.

Bien que ces formulaires aient inclus dans la pagination, il n'y aura aucun contenu manquant.

\section{Canadä}




\begin{abstract}
$\underline{\text { Abstract }}$
While fat occurs naturally in humans, the financial burden excess fat places upon North American governments has spurred a massive regulatory strategy aimed at reducing the physical size of American and Canadian citizens. The central question addressed within this thesis is how the governance of obesity is able to be executed within the human body. It is through the use of a theoretical framework consisting of moral panic, governmentality and its derivative of problematization, that I address the motivations behind the governments' regulation of obesity. Furthermore, I also account for the North American public's active compliance to the intimate forms of physical regulation presented by obesity governance. As a consequence of this study, the success of the regulatory strategy found within the United States and Canada is established to be dependent upon a vast array of formal and informal regulatory tactics and the accompanying compliance of the North American public.
\end{abstract}




\section{Acknowledgments}

I would like to thank my family and friends for their endless patience. I would also like to recognize my supervisor Peter Swan for his ability to transform my uncertainty and fury into positivity and progress, as well as Sheryl Hamilton, Michael Mopus, and Doris Buss for sitting on my defence committee.

Furthermore, I extend massive gratitude to Josie Pirslin for keeping me edited, fed, and motivated through her occasional yelling, Bruce Springsteen, and most importantly Mary Black. 


\section{Table of Contents}

Abstract

Acknowledgments

Introduction

Chapter I: A Literature Review

Stigmatization of Obesity

Paternalism

Methodology

Chapter II: From Private to Public: A Moral History of Fat 25

The History of Obesity

The Problematization of Fat

Chapter III: Moral Panic and the Extension of Obesity Governance 44

Stanley Cohen's Moral Panic Theory

The Moral Panic of Obesity

Who Started this Fat Panic?

Expanding the Epidemic

Chapter IV : Governmentality \& Obesity 67

Foucault's Governmentality

Responsibilization

Governmentality and the Governance of Obesity

Policy and Legislation

Conclusion 


\section{Introduction}

My beloved blue, furry monster - who sang "C is for cookie, that's good enough for me" - is now advocating eating healthy. There's even a new song - A Cookie Is a Sometimes Food, where Cookie Monster learns there are "anytime" foods and "sometimes" foods. ${ }^{1}$

Throughout the United States and Canada, the current expression being commonly used to describe the rising rates of obesity is that of an epidemic. It is this epidemic that as both North American governments claim, presents a major threat to the lives of everyone. Having been born in the mid 1980's, coinciding with the advent of the personal computer, I have grown up immersed in the wired and convenience-based generation, where work is more prone to involve the use of a comfortable chair than that of a shovel. Although I spend far more time engaged in stationary activities than I do being physically active, I have yet to become even remotely obese. Furthermore, while my failure to become excessively fat is due to a multitude of variables ${ }^{2}$, contrary to the pressing immediacy found within the government's warnings of what it urges is a sweeping epidemic, obesity does not strike overnight; obesity is often the result of a number of medical issues or lifestyle choices, that culminate in becoming overly corpulent.

However, even though I am able to remain at what I believe is an acceptable weight, when Canada's ParticipACTION initiative spokespersons Hal Johnson and Joanne McLeod appear in their Body Break segments spouting the benefits active living, I am filled with the guilt of my lethargy; and as result often repent by means of the gym.

\footnotetext{
${ }^{1}$ C. Carter, Cookie Monster: 'Me eat less cookies' Associated Press June 42005. http://www.usatoday.com/life/television/news/2005-04-07-cookie-monster_x.htm ${ }^{2}$ such as metabolism, diet and genetics
} 
How is it that even in the confidence of my own weight, I still can be so easily manipulated by the anti-obesity agenda found within North America?

In the face of increasing rates of obesity, North American governments are attempting to stave off the weight gain of their population through multifaceted forms of governance. The use of Sesame Street's Cookie Monster to spout lessons of food moderation to American and Canadian children is just one example of the many forms of governing strategies being utilized to stop the growth of the alleged obesity epidemic sweeping North America. ${ }^{3}$

While the majority of individuals consider the existence and amount of fat tissue lurking beneath their skin a private issue, it is anything but. The physical fat content of millions of people, adults and children, is now the primary concern of American and Canadian governments. Furthermore, unlike the issue of smoking where regulation is put in place to impede the consumption of cigarettes, what makes the issue of the governance of obesity so fascinating is that governments are effectively commandeering fat, an organic substance which occurs naturally within the human body, as a means of controlling human populations.

Central to the governance of obesity is the question of how North American governments are able to assert their authority within the physical bodies of their populace. Furthermore, how does this internal control become justified by citizens as necessary to public welfare? And finally what is the best method to mask the intrusiveness of regulating one's body size? In order to successfully implement policies which supersede human autonomy and regulate the physical size of one's body, the

\footnotetext{
${ }^{3}$ While not a direct government initiative the message of Sesame Street's Cookie Monster is certainly in the same vein as the efforts of North American governments to discourage children from becoming obese.
} 
government must provide some impetus for acceptance or else such efforts to decrease rates of obesity would be met with resistance.

It is through a combination of theory and analysis that I will establish why North American governments are able to utilize human fat as a tool to govern American and Canadian populations. Furthermore, rather than simply focus on the government motivations for regulating obesity I will examine why the governments' acquisition of human fat has become accepted by North American society. In order to fully explore the rationale behind the government's need to regulate obesity and account for the accompanying receptiveness of the North American population, I will employ a method of analysis which synthesizes the government's want to regulate with the desires of the population to be regulated.

To account for the current regulatory climate surrounding obesity and the view that human fat is considered a matter of state importance a threefold approach must be taken; it is by combining theories of problematization, moral panic, and governmentality that the North American approach to the control of obesity becomes apparent. It is through the governance of an intrinsically shared human characteristic such as fat, that North American government's gain the ability to regulate virtually everyone enabling them to alter mass behaviour for primarily economic purposes.

The first concept being used to examine the relationship between obesity and governance is problematization. As fat tissue exists naturally within the body, it is not an inherently legal issue, a connection between formal methods of governance and fat must be provided which accounts for why human fat became legalized through the medical 
classification of obesity. ${ }^{45}$ This attachment of law onto obesity can be accomplished through a series of problematizations. Furthermore, the problematization of obesity transforms the previously private subject of body fat into a viable method through which government's are able to administer control over the human body. The importance of the problematization of obesity is that it provides a link between law and the governance of the human body; thus connecting governments' ability to gain access into the formerly private issue of human weight. Without the connection between law and obesity, insight into the ability of government authorities to assert their dominance within the bodies of North American citizens would not exist.

The current rise in social anxiety and the resulting expansiveness in human governance can be rationalized using moral panic theory. The moral panic regarding obesity is a by-product of the stigmatizations illuminated by the problematization of obesity, and given the current regulatory climate surrounding obesity it becomes apparent that fat which occurs naturally in the human body has become transformed into a daunting threat. More importantly those who are overweight have become perceived as a dangerous demographic. It is through a moral panic that historically held insecurities concerning obesity reach an unprecedented level of excess and high levels of governance become deemed socially necessary. The problematization of obesity provides an entrance for the state into the bodies of its citizens however, it does not account for why the governance of obesity has become so extensive.

Furthermore, while problematization and moral panic theories provide both method and scope for the governance of fat, they lack an adequate technique for the

\footnotetext{
${ }^{4}$ Legalized in this sense refers to a non-legal problem becoming legal.

${ }^{5}$ The term obesity is being used to describe an individual with a Body Mass Index of thirty or higher.
} 
implementation of regulation. With an issue such as obesity, the controlling of something as intimate as the fat content of one's body must be done cautiously and in a manner that will mask the intrusiveness of dictating the proper diet and lifestyle of North American citizens. The government's cunning approach to the regulation of obesity is illuminated through the application of Foucault's governmentality. Central to governmentality is the government's ability to regulate the behaviour of an entire population through a wide array of control techniques all aimed at a singular goal. In this case, the goal of the vast spectrum of regulations aimed at obesity is to increase the ability of citizens to execute government policies, by means of improving the economy rather than exhausting it.

It is by interlocking the problematization of obesity, moral panic and governmentality that human fat can become governed. More revealing is how this structure represents a means from which populations can be willingly controlled from the inside. While singularly each theory does little to explain why obesity has become exceedingly governable, the combination of each selected theory towards the current issue of obesity provides an imperative answer as to why Canadian and American bodies have exposed themselves to state control, as well as the state impetus for implementing such control. 


\section{Chapter I: A Literature Review}

The definition of obesity, in the most technical sense is fairly straight forward.

Obesity is the medical categorization of a Body Mass Index exceeding thirty. ${ }^{6}$ However, as the existing body of literature illustrates, the idea of attempting to regulate something as fundamentally personal as body size and daily food intake is fraught with complexities. How can a government alter the physical fat content of millions of people through such seemingly heavy handed measures of modifying diet and lifestyle without facing resistance?

By dividing the existing literature into the themes of stigmatization and paternalism, a significant gap becomes exposed within the existing literature; the academic discourse surrounding obesity fails to account for the process by which stigmatization $^{7}$ and paternalism ${ }^{8}$ can be amalgamated into an accepted form of governing strategy. Furthermore, the scholarly discourse neglects to construct a process through which this stigmatization of the obese makes them a socially accepted target for regulation. By first examining the body of literature pertaining to stigma followed by paternalism I will fill in the gap found within the existing body of research through the amalgamation of informal forms of governance such as stigma with paternalistic methods of governing. Furthermore, in combining stigma and paternalism, an alternate approach is produced which addresses the more important issue of how stigma and paternalism can be transformed into a more palatable form of governance from which governments are able to control human fat content without seeming overly intrusive.

\footnotetext{
${ }^{6}$ International Obesity Task Force, “'Global strategies to prevent Childhood obesity: Forging a societal plan that works" A discussion paper prepared for the Global Prevention Alliance McGill Integrative Health Challenge October 26-27 2006 at 21.

${ }^{7}$ To be disfavoured by society because of a trait such as excess fat

${ }^{8}$ Government centered forms of health regulations
} 


\section{The Stigmatization of Obesity}

The literature concerning stigma illustrates the powerful relationship between stigmatization and obesity, such as how the act of stigmatization removes obese people from accepted society and casts them as outsiders. A focal point of the scholarly discourse on the non-medical effects of obesity has been the moral and social stigma that accompanies it. By outlining the literature surrounding the stigmatization of obesity the boundaries of the research become obvious, the respective authors fall short of drawing a connection between stigma and governance. It is by examining the literature concerning the stigmatization of obesity, that existing research can be utilized to construct an alternative framework. It is within this framework that the informal governing aspects of stigma can be connected to the formal regulatory strategy currently being utilized by North American governments to regulate the bodies of millions of Canadian and American citizens.

An early study by Werner J. Cahnman ${ }^{9}$ attempts to construct a typical model of the way obesity is stigmatized. Cahnman argued that any medicalization of obesity would result in an inadequate solution. According to the author, unless the stigma of being obese was removed and those who were considered grossly overweight were instilled with a sense of adequacy in being human beings, medical solutions will prove short term and ineffective. $^{10}$

\footnotetext{
${ }^{9}$ W. Cahnman, "The Stigma of Obesity", The Sociological Quarterly (Summer 1968) Vol. 9. No. 3at 283299.

${ }^{10}$ Ibid.
} 
Cahnman defines his approach to stigmatization as "rather than being an attribute of the deviant, [deviance] becomes a label attached to a person by others." 11 In focusing his approach around stigma rather than deviance, Cahnman adapts Edward Lemert's theory of deviance ${ }^{12}$ to more aptly suit society's reaction to obesity. In order to explain the effect of stigmatization on an individual, the author applies his adaptation of Lemert to sociological theories of Erving Goffman. ${ }^{13}$

Goffman, who was concerned with the ways people interact based on the presentation of self, states that the majority of people who interact with a stigmatized individual "fail to accord him the respect and regard which the uncontaminated aspects of his social identity have led him to anticipate extending, and have led them to anticipate receiving; he echoes this denial by finding that some of his attributes warrant it."14 This statement is essential in furthering Cahnman's aim in applying Goffman's theory to obesity, for the cycle of stigmatization is complete when the obese person feels the discrimination brought against him or her is both justified and deserved. ${ }^{15}$ While Goffman fails to include obesity in his study of physical disorders that instigate stigma, Cahnman stresses that a disability such as obesity is just as serious, claiming that "the disability connected with obesity does not seem overly serious...[however,] the obese are presumed to hold their fate in their own hands... While blindness is considered a misfortune, obesity is branded as a defect." ${ }^{16}$ The importance of Cahnman and Goffman

\footnotetext{
${ }^{11} \mathrm{Ibid}$. at 293.

${ }^{12}$ M. Lemert Social Pathology (New York: McGraw Hill, 1951)

${ }^{13}$ E. Goffman, Stigma: notes on the management of spoiled identity (Englewood Cliffs, N.J.: Prentice Hall 1963) at 8-9.

${ }^{14}$ Ibid.

${ }^{15}$ Cahnman at 293.

${ }^{16} \mathrm{Ibid}$. at 294.
} 
to my project is that they collectively provide a framework that accounts for the stigmatization of obesity within the medical profession.

Beatrice Kalisch ${ }^{17}$ expands on Cahnman's ideas, while again drawing heavily from Goffman's stigma theory. Unlike Cahnman rather than simply focus on the consequence of stigmatization, Kalisch explores the impetus behind why human beings stigmatize others. Kalisch theorizes that the innate human need to stigmatize those who are different is a defence mechanism to deny our common vulnerability with those afflicted. ${ }^{18}$ In order to support her position, the author references two studies which examine the link between stigma and obesity. Both studies involved the ranking of images of marginalized persons from most desirable to least. In a study undertaken by S. Richardson on cultural uniformity and physical disability ${ }^{19}$ six hundred and fifty children aged ten to eleven years of age were shown six drawings of kids ranging from a child with no handicap, to various physical handicaps and an obese child. The results were almost unanimous; the "normal child" was ranked the most socially desirable, while the obese child being most often ranked the least desirable. ${ }^{20}$ A similar study was conducted by G.C. Maddox utilizing adults rather than children. Analogous results followed, with the obese child once again being ranked the lowest. ${ }^{21}$ Maddox attributed this low ranking to the perception that obese individuals were held responsible for their condition while people with handicaps such as missing limbs were not. ${ }^{22}$

\footnotetext{
${ }^{17}$ B. Kalisch, “The Stigma of Obesity” The American Journal of Nursing (June 1972) vol. 72 No. 6 at 1124-1127.

${ }^{18} \mathrm{Ibid}$. at 1125

${ }^{19}$ S, Richardson. "Cultural Uniformity and Reaction to Physical Disability" Am. Sociol Rev (1961) 26 at 241-247.

${ }^{20}$ Ibid.

${ }^{21}$ G, Maddox. 'Overweight and Social Deviance and Disability"Journal of Health and Social Behaviour. (Dec 1968) Vol. 9 at 287-298.

${ }^{22}$ Ibid.
} 
William DeJong also draws upon Goffman in his analysis of obesity. ${ }^{23}$ DeJong utilizes Goffman's theory of spoiled identity which posits that stigmatized individuals are viewed as sub-human and are thus subject to increased discrimination. ${ }^{24}$ Rather than rely on solely upon Goffman's ideas of stigmatism, the author references an article by E. Langer, which differentiates between forms of stigma. He asserts that "Langer and her associates point out that those with a so-called characterological stigma typically have acquired their deviant status through the commission of deviant acts." ${ }^{25}$ What accompanies this characterological stigma is the perception that the deviant individual plays an active role in attaining and maintaining their deviant status. ${ }^{26}$ DeJong contrasts the characterological form of stigma with that of physical stigma, arguing that a perception of blame for those with a physical stigma is relatively rare. ${ }^{27}$ However, unlike physical stigmas that are perceived predetermined or beyond human control, DeJong presents obesity as an example of a physical stigma that carries with it an extremely negative human prejudice.

DeJong reasons that in the case of obesity, negative judgments arise from the belief that the obese are to blame for their own condition. DeJong concluded that "unless the obese can provide an excuse for their weight, such as a thyroid condition, or can offer evidence of successful weight loss their character will be impugned."28

\footnotetext{
${ }^{23}$ W, DeJong, "The Stigma of Obesity: The Consequences of Naïve Assumptions Concerning the Causes of Physical Deviance" Journal of Health and Social Behaviour (1980) Vol 21 at 75-87.

${ }^{24}$ Ibid at 75 .

${ }^{25}$ E.J., Langer, et al. "Stigma, Staring, and Discomfort: A novel stimulus and hypothesis" (1976) Journal of Experimental Psychology, 12 at 451-63.

${ }^{26}$ E. Jones, and K.E. Davis "From acts to dispositions: the attribution process in person perception" in Leonard Berkowitz (ed.) Advances in Experimental Social Psychology, Vol 2 New York: Academic Press at 219-66.

${ }^{27}$ Dejong at 76 .

${ }^{28}$ Ibid. at 85.
} 
Sociologists Deborah Carr and Michael Friedman ${ }^{29}$, take a much broader approach to the concept of stigma. Carr and Friedman challenge the previous discourse surrounding the stigma of obesity, arguing that

Prejudicial attitudes alone are not sufficient evidence that a personal attribute such as obesity is stigmatizing. Rather, the stigma process also may encompass both the actions of individuals and agents of social institutions who denigrate and exclude, as wells as the reactions of persons in the devalued social category. ${ }^{30}$

In expanding the concept of stigma, ${ }^{31}$ Carr and Friedman put into question whether or not obese people experience discrimination, a critical component of stigma. Unlike previous studies which focused upon how society perceived obese people, Carr and Friedman's emphasis is on how the obese perceive they have been discriminated against. The authors concentrate on reports of multiple forms of discrimination, such as: major discrimination (i.e. being denied a job promotion), day-to-day interpersonal discrimination (i.e. minor slights that cause distress), and institutional discrimination (i.e. negative attitudes held by health care professionals). ${ }^{32}$

The authors deduce that while obese individuals are a stigmatized group, they also perceive themselves as a target for discrimination. This perception of intolerance has negative implications for their psychological well being. ${ }^{33}$ Carr and Friedman theorize that the belief that one is a target of discrimination due to a personal attribute such as weight, may explain why some persons with stigmatized identities have more negative

${ }^{29}$ D. Carr and M. Friedman, “'Is Obesity Stigmatizing? Body Weight, Perceived Discrimination and Psychological Well-Being in the United States" Journal of Health and Social Behavior (Sept. 2005) vol 46 No 3 at $244-259$

${ }^{30}$ Ibid. at 244.

${ }^{31}$ B. Link and Jo C. Phelan "Conceptualizing Stigma" (2001) Annual Review of Sociology 27 at 363-85.

${ }^{32}$ Carr and Friedman, at 246.

${ }^{33}$ Ibid. at 253 . 
self-evaluations than 'normals, ${ }^{34}$ thus adding causation to Goffman's theory about the self inflicted deprecation of those with a physical stigma. ${ }^{35}$ It is through Carr and Friedman's conclusions concerning the internalization of stigma that a justification may be provided between the obese and the acceptance of governance. If the obese individual internalizes the stigma present within North American society, through the process of self stigmatization they will be more likely to subject themselves to anti-obesity governing measures.

While Cahnman and DeJong adapt Goffman's study of stigma to obesity, both authors are primarily focused upon the affect of stigmatization upon the obese. Furthermore, Kalisch examines the implications of why humans stigmatize each other, and Carr and Friedman focus their study upon prevalence of obese people to internalize outside stigma which is directed at them. Rather than attempt to connect the effects of stigmatization to anything peripheral, the literature concerning obesity and stigma fails to examine the greater ramifications of stigma that lay outside of the obese individuals' relationship with themselves and non-obese society. By neglecting to examine the impact of stigma on issues extending away from obese individuals and their affiliation with society, the larger role that stigma plays in matters such as governance remains unexplored within the scholarly literature. It is by utilizing the existing research concerning the affects of stigma projected externally by society, and internalized by obese individuals onto themselves, that I am able to create an approach to the regulation of fat which identifies stigma as a means through which formal obesity laws are brought into fruition.

\footnotetext{
${ }^{34}$ Ibid. at 255.

${ }^{35}$ E. Goffman, Stigma: notes on the management of spoiled identity (englewood cliffs, N.J.: Prentice hall 1963)
} 


\section{$\underline{\text { Paternalism }}$}

The paternalistic involvement of North American governments' in obesity based health interventions often results in strong public dislike. ${ }^{36}$ By reviewing the literature surrounding obesity and paternalism, one is able to scrutinize the nature of their often contested relationship. While the topic of obesity and government intervention has been written about before, little attention has been paid to the ways in which existing social stigmas can actually garner public support for government intervention.

Phillip Cole challenges the ethics of health based interventions. ${ }^{37}$ Cole stresses the importance of examining the moral underpinnings of the usually endorsed public health interventions, and argues that personal intrusion to stop the prevention of disease should ideally require some form of moral justification. Cole's reasons for requiring a moral rationalization for public health interventions are threefold: firstly most interventions are enforced by government authority; therefore non-compliance may result in an individual being subject to state prosecution; ${ }^{38}$ second, most public health interventions are financially supported via tax funds, and lastly public health preventions are often intrusive and meddlesome. Cole maintains that as such intrusions are backed with public funds they have the ability to offend America's social contract, undermining inalienable rights to liberty and personal autonomy.

While interventions such as preventative health education, policy advocating, taxation, legislation and research, seem like mechanisms that promote a common wellbeing, Cole contends that they are forms of paternalism. Described by Cole as being

\footnotetext{
${ }^{36}$ L. Gostin, “Law as a tool to facilitate healthier lifestyles and prevent obesity"(2007) JAMA. Jan 3, 297 at 90 .

${ }^{37}$ P. Cole, “The Moral Bases for Public Health Interventions “ Epidemiology, (Jan, 1995) Vol 6. No 1. At 78-83.

${ }^{38} \mathrm{Ibid}$. at 78 .
} 
"most odious when used as a justification for limiting the choices that adults make in their everyday lives" ${ }^{39}$ paternalism if imposed on unwilling adults, negates any moral basis for health regulation. Cole's stance on the resistance of individuals to health based interventions is very much in line with my own view of the possible contentions present within the governance of obesity. Cole argues that to avoid public resistance to government sanctioned health measures, any health initiative should be carried out in an inconspicuous manner while being accompanied with a public desire to be governed. It is within the following chapters that governmentality and moral panic theory will be utilized to further clarify the often contentious relationship between government health initiatives and the governed public.

Like Cole, Soren $\mathrm{Holm}^{40}$ further examines the tensions between the roles of the state, public health, and the individual; however, Holm narrows his focus to that of the paternalism of health interventions and obesity. The first ethical problem that Holm highlights is "whether and when it is justifiable to intervene to promote a person's own health or well-being, if they do not want the intervention...The second is whether and when it is justifiable to negatively affect a person or people's well-being in order to benefit others or to promote the common good." 41

Holm adopts Finnish philosopher Heta Hayry's conceptualization of three different levels of paternalism: hard paternalism, soft paternalism, and maternalism. ${ }^{42}$ Hard paternalism entails direct coercion, while soft paternalism involves giving unwanted information in order to alter behaviour, and maternalism is a form of control by inducing

\footnotetext{
${ }^{39}$ Ibid. at 81 .

${ }^{40}$ S. Holm, “'Obesity Interventions and Ethics" Obesity Reviews (2007) 8. (Suppl. 1). at 207-210.

${ }^{41}$ Ibid. at 207.

${ }^{42} \mathrm{H}$. Hayry, The Limits of Medical Paternalism. (Routledge: London, 1991)
} 
a guilty conscience. ${ }^{43}$ Hard paternalism requires a stronger justification as it involves the denial of self determination. While soft paternalism sets out to influence, but not overthrow one's expression of free choice. To illustrate his use of soft and hard paternalism Holm alludes to smoking. He states, "If smoking bans in public places had been justified in terms of their health benefits to smokers, it would have been an example of soft paternalism which gradually edged into hard paternalism as more and more areas became non-smoking."44

Holm examines the difficult dichotomy between hard paternalism and informed rational choices that he argues, ought to be respected. While becoming obese may be considered a foreseeable consequence of one's choices and actions, it is complicated by socialization, and the difficulty of radically changing one's lifestyle. However, obese individuals may genuinely enjoy the way they live and accept future health risks as a reasonable trade-off for present satisfaction. ${ }^{45}$ Holm utilizes such tension, to illuminate how large-scale health interventions effectively increase social stigma and unjustly treat the obese by criticizing how their often informed life choices negatively affect the rest of society. Moreover, the inability to limit the scope of health interventions to affect only those at risk suggests that in order to target a high risk demographic such as the obese, health promotions will be directed at the entire population. Therefore rather than view the governance of obesity as aimed only at the excessively overweight, any health incentive aimed at reducing obesity must be viewed as placing an onus to avoid obesity upon the entire population. In order to account for the governance of the entire population, it is

\footnotetext{
${ }^{43}$ Holm at 207.

${ }^{44}$ Ibid. at 208.

${ }^{45}$ Ibid. at 209.
} 
through a moral panic that my framework accounts for the governance of not just the obese, but the potentially obese.

The Elephant in the Room: Evolution Behavioralism, and Counteradvertising in the Coming War Against Obesity, ${ }^{46}$ a note published by the Harvard Law Review examines anti-paternalistic regulatory approaches for controlling obesity. Rather than view humans as independent actors, this note argues that human beings are easily subject to persuasion by means of advertising. The authors attribute this lack of behavioural independence to the existence of systematic flaws in human rationality and refer to it as behavioralism, ${ }^{47}$ "currently, behavioralism is a loose collection of research findings that undermine two basic tenets of modern economics: that human beings are rational actors and that people's preferences are determined outside the market." ${ }^{48}$ Furthermore, the scholars who published The Elephant in the Room: Evolution Behavioralism, and Counteradvertising in the Coming War Against Obesity utilize behavioralism to contend the opposite.

Central to behavioralism is the notion that the preferences of humans are not predetermined or fixed but easily manipulated by immediate gratification. ${ }^{49}$ As a result behavioralists argue that human preferences are easily swayed by means of advertising; based on this, those who advertise food products are thought to be ideally positioned to exploit the consumer and promote unhealthy lifestyles. ${ }^{50}$ The authors state that

advertisers can market the good taste of [unhealthy] foods ... while misleading consumers about the health risks their products pose. If an

\footnotetext{
${ }^{46}$ Harvard Law Review“The Elephant in the Room: Evolution Behavioralism, and Counteradvertising in the Coming War Against Obesity“ (Feb, 2003) Harvard Law Review, Vol 116 No. 4. at 1161-1184.

${ }^{47}$ Behavioralism is defined by the authors as "a loose collection of research findings that undermine two basic tenets of modern economics: that humans are rational actors and that people's preferences are determined outside the market" Harvard Law Review at 1164. ${ }^{48}$ Harvard Law Review at 1164.

${ }^{49}$ J. Hanson, and A Kaysar, "Taking Behavioralism Seriously:Some Evidence of Market Manipulation" Harvard Law Review (1999) at 1420.

${ }^{50}$ Harvard Law Review at 1170.
} 
advertiser extols the great taste of its product, and simultaneously makes spurious claims about the health consequences - or even remains silent about the risks involved - consumers are likely to misperceive the long-term health effects of the product. $^{51}$

Furthermore, the negative long-term effects of unhealthy food choices are often passed over for immediate satisfaction. As a result the individual believes that if they indulge now they will diet later. However this promise of future moderation rarely comes to fruition and works to validate their present action of overeating, while successfully fulfilling the advertiser's marketing strategy.

In order to delve into the thought process of the actor, the authors turn to economist David George $^{52}$ who claims that individuals have first and second order preferences. First order preferences are the decisions that people act on, while second order preferences are what motivate the action. ${ }^{53}$ It is these first order preferences that the authors at the Harvard Law Review claim are so easily manipulated by advertising, which as George argues negatively alters our first order preferences. The visceral impact of food advertising combined with hunger is said to override first and second order preferences that may have previously been a healthier option, leading the consumer to a fatty end.

The authors of this note contend that the implementation of paternalism on issues of self identity should be met with fierce resistance; however, they nonetheless view paternalism as both multifaceted and complex. While being legally required to wear a seatbelt is a form of strong paternalism, it does little to offend our core ideas of selfidentity; this is not the case with regulation of diet. The authors contend that even in

\footnotetext{
${ }^{51}$ Ibid.

${ }^{52}$ D. George, Preference Pollution: How Markets Create the Desires We Dislike (University of Michigan Press: 2001)

${ }^{53}$ Harvard Law Review at 1169.
} 
cases such as obesity where the harm imposed on society may be catastrophic, regardless of the benefits, some forms of paternalism are simply intolerable. Even though the writers of this note are considerably hesitant concerning combining paternalism and diet, given the manipulation of human beings by advertising, they argue that government intervention to restore voluntary choice may be acceptable. ${ }^{54}$ The authors maintain that an acceptable form of regulatory action in response to obesity would be for the government "to remove obstacles to autonomous decision making rather than impose decisions on its citizens that run counter to their preferences...Second, the government should favor policies that do not strike at the core of self-identity."55

Charlene Elliott ${ }^{56}$ counters the behavioralist approach taken by the Harvard Law Review by focusing on the ability of individuals to utilize their intelligence to dissect the underlying motives of advertising. Elliott examines the relationship between children, obesity and food. Rather than harp on obvious targets such as fast food, or junk food, Elliott examines supermarkets as the primary environment from which children learn to become food consumers. It is within the supermarket setting that children are bombarded with the child specific advertising of fun foods. Elliott defines fun food as, "a category of products which use shape, colour, size, package iconography and graphics and language to identify their status as children's fare and/or fun., ${ }^{, 57}$ Whereas parents view fun foods as a desirable way to appease their children, they often do not realize that such foods are often devoid of any nutritional benefit. While authors such as those at the Harvard Law Review may have simply linked fun foods as a major causation of childhood obesity,

\footnotetext{
${ }^{54}$ Ibid. at 1176 .

${ }^{55} \mathrm{Ibid}$. at 1177 .

${ }^{56}$ C. Elliott, “Childhood Obesity and our Toxic Environment: Suggestions for Future Research“ Journal of Family and Consumer Sciences Education, (2005) 22(3). 47-51.

${ }^{57}$ Ibid. at 48 .
} 
rather than target food manufacturers Elliott claims that it is up to educators to provide knowledge to both parents and children about proper nutrition. This food education will both enable the consumers to intelligently navigate through the food environment of the supermarket, as well as empower them to make informed choices concerning their children's diet on the basis of health rather than clever advertising.

Previous authors argued that a paternalistic stance on food consumption is both unethical and unattainable; however, Richard Daynard ${ }^{58}$ contends that in the absence of government regulation, litigation aimed at the food industry is the answer. Daynard compares the future of successful obesity litigation to that of tobacco which depended upon the wrongdoings of the manufacturers. However, Daynard is quick to highlight the differences; while tobacco is harmful when consumed, food is essential for survival. It is Daynard's goal to utilize the legal system to regulate corporate practices such as advertising that cannot be targeted by means of paternalism.

Daynard claims that the lawsuits exercising consumer protection against food manufacturers will promote consumer awareness as well as industry self-policing. Furthermore, the author argues that litigation will stop unfair and deceptive trade practices such as the promotion of high calorie food under the guise of being nutritionally beneficial. ${ }^{59}$ An alternative route of food litigation presented by Daynard is personal injury claims which provide relief to consumers harmed by a food product which was either defective or marketed improperly. The basis for Daynard's argument can be traced to the improper marketing theory which as he states, "requires that the seller deceived the

\footnotetext{
${ }^{58}$ R. Dayner et al, “Private Enforcement: Litigation as a tool to Prevent Obesity“(2004) Journal of Public Health Policy Vol. 25 No $3 / 4$ at 408-417.

${ }^{59}$ Committee on Children's Television, Inc. v. General Foods Corp. (1983) 35 Cal.3d 197, 209- 210, 197 Cal.Rptr. 783, 673 P.2d 660.
} 
consumer in a material way about the health effects of eating the food, and that this deception is what caused the consumer to consume the food. ${ }^{, 60}$ Moreover, the onus would be on the consumer to prove that his obesity was a direct result of consuming the food in question and, as a result, the obesity caused a subsequent medical problem.

While Daynard claims that industry targeted litigation is a suitable alternative to food based paternalism he fails to demonstrate how it is feasible, citing failed lawsuits ${ }^{61}$ and tort reform granting the food industry legal immunity. ${ }^{62}$ However, as obesity rates continue to increase, well-founded law suits may become equally as prominent, proving Daynard's vision of a food industry forced into reform by litigation a reality.

In his article, "Law as a Tool to Facilitate Healthier Lifestyles and Prevent Obesity", ${ }^{63}$ Gostin identifies the challenges of implementing government sanctioned obesity preventative measures. Even though obesity stems from a person's own behaviour due to the high economic costs placed upon taxpayer financed medical plans, Gostin states that "the government arguably has a legitimate interest in controlling medical and social costs of individuals' unhealthy behaviors that are borne by society at large. ${ }^{\prime 64}$ Even in supporting paternalistic anti-obesity measures extending from diabetes surveillance to the taxation of unhealthy foods to outright food prohibitions, ${ }^{65}$ Gostin admits that while people generally dislike paternalism, paternalist interventions provide a means of regulating self imposed harms which then harm the rest of society. ${ }^{66}$

\footnotetext{
${ }^{60}$ Dayner, at 412 .

${ }^{61}$ Pelman v. McDonald's Corp., 237 F.Supp. 512 (S.D.N.Y. 2003).

${ }^{62}$ Dayner at 412.

${ }^{63} \mathrm{~L}$. Gostin, "Law as a tool to facilitate healthier lifestyles and prevent obesity"(2007) JAMA. Jan 3, 297

${ }^{64}$ Gostin at 87.

${ }^{65} \mathrm{Ibid}$. at 90.

${ }^{66} \mathrm{Ibid}$.
} 
As conveyed by the literature concerning obesity and paternalism, the involvement of the government with an issue that involves components which influence how people eat and raise their children is unsurprisingly met with tension. However, how can paternalistic forms of governance be enacted without seemingly challenging one's personal autonomy? While the literature examines many of the complexities present within government health interventions, it fails to come to a conclusion about whether or not paternalistic measures should be utilized in the name of anti-obesity regulation. Furthermore, with regards to Gostin's argument that paternalism does have a place within the governance of obesity, other than conveying that the implementation of such regulations will be troublesome, he neglects to elaborate on a method by which paternalistic methods of governance can be productively utilized to hinder the growth of obesity. Whilst Holm connects paternalistic methods of obesity governance with stigma, rather than viewing stigma as a possible means through which paternalistic forms of governance can be implemented, she views paternalism as a catalyst that increases the amount of social stigma faced by the obese.

In order to fill the gap in the existing academic discourse between obesity, stigmatization and paternalism, I will utilize the problematization of obesity as a point at which law becomes attached to the previously non-legalized ${ }^{67}$ issue of human body fat. Through the creation and implementation of a framework that includes moral panic theory and governmentality, it becomes apparent that stigmatization can be transformed into a central component of obesity governance. Furthermore, it is as a result of the relationship between stigma and paternalism that concern about personal autonomy

\footnotetext{
${ }^{67}$ The terms legal and legalization are being used to describe the attachment of law onto the issue of fat and obesity.
} 
becomes secondary and a foundation is laid for regulation.

\section{$\underline{\text { Methodology }}$}

This section is a means of elaborating on the methods of research I will use in addressing why and how North American governments are able to utilize human fat as a method of governing American and Canadian populations. The method of research employed throughout this paper is a threefold approach which focuses upon the study of the governance of obesity through the theoretical lenses of governmentality and problematization, and moral panic.

While the combination of governmentality and moral panic may be argued as potentially problematic, I will utilize each model to accomplish a separate function. Whereas problematization ${ }^{68}$ will be used to attach law to human fat, moral panic will address the public's compliance to obesity governance. The final theory used is governmentality, which will account for a governing strategy from which obesity governance can be implemented. Due to the ambitious nature of my framework some potential issues that may occur in attempting to synthesize the differing theories to explain the emerging governance of fat is the disparity between theory and the governance of fat.

As a means of linking theory with the governance of fat, certain assumptions have been made about the relationship of North Americans with fat, such as the influence of obesity governance is the only incentive for individuals to adopt healthy life styles. As the term 'North American' citizens refers to everyone who lives within America and Canada I approach the targets of governance in a monolithic manner that does not take into consideration the existence of any differing relationships with obesity governance.

\footnotetext{
${ }^{68}$ A derivative of governmentality
} 
Even though America and Canada have taken different approaches to the governance of obesity, rather than focusing on the dissimilarities of each country's governing techniques, the scope of my analysis focuses on the analogous approach of both the United States and Canada in the high prioritization of obesity governance. Furthermore because my framework is directed at the ability of governance to alter the conduct of North American citizens, it does not account for individuals or groups who actively dissent against health based governance which as its goal seeks to reduce the fat content of North American bodies through obesity mitigating regulations.

As the primary focuses of this thesis is the governance of the human body through fat, it is important to clarify my usage of terms and differentiate between the use of the terms fat and obesity. In addressing the governance of fat the two terms can easily be confused and wrongly interchanged. While the term 'fat' refers to the biological substance found within the body, it should be understood that the phrase 'obesity' is understood in this thesis as a purely medical construct used denote a category of the over 30 within the body mass index scale.

While the issue of excess fat and the classification of individuals as medically obese is a complex topic, rather than raise issues concerning the multitude of factors which cause individuals to become fat and considered obese I raise issues which are related but focus my analysis on how the social construct of obesity can be utilized as a means of governing the biological component of fat.

Within my framework of problematization, moral panic and governmentality, there is an underlying component of risk. Pat O'Malley argues that we live in a society which governs according to potential risks. ${ }^{69}$ He claims that, "science and expertises based on ${ }^{69}$ P., O’Malley, Crime and the Risk Society (Aldershot: Ashgate, 1998). 
science are rendered responsible for the definition of risks, the establishment of standards of acceptable risk, and for making the population think in terms of risk: health and safety...at work and in out diet.",70

O'Malley argues that the risk society has replaced the class society, in that rather than base society upon the distribution of wealth; society is now more concerned with the distribution of risks. ${ }^{71}$ As will be seen in the following chapters, the notion of risk is found within the medicalization of obesity and is extensively over exaggerated within a moral panic. While financial and medical risk is a principal function behind the desire to regulate obesity, the discussion of risk and its function within the governance of obesity remains beyond the scope of my analysis of the creation of governmental strategies.

Through the use of Foucault's governmentality I am able to argue that American and Canadian governments can utilize a wide array of governing techniques from which alter the conduct of North American citizens. However, rather than focus upon nongovernmental sources of obesity governance, I will concentrate on government created and influenced regulation. By analyzing government influenced obesity governance I am able to draw a parallel between the problematization of fat and the implementation of formal regulation by formal governing bodies such as American and Canadian governments. While anti-obesity targeted forms of informal governance do come from sources other than North American governments, I view outside regulatory attention as secondary to that of formal governing bodies.

${ }^{70} \mathrm{Ibid}$ at 1.

${ }^{71}$ Ibid at 1. 


\section{Chapter II: \\ From Private to Public: A Moral History of Fat}

In an episode of The Simpsons entitled King-Sized Homer, Lisa defends her then obese father by shouting, "Just because he's overweight doesn't mean he's bad.,"72 While this statement is situated within the contemporary context of pop culture, the relationship between morality and excess body weight can be traced to biblical times. It is interesting to follow the progression of how the intensely private issue of body fat (or more specifically body lipids) has become transformed from a physical component into a public problem. In order to examine how stigmas can become formalized into law I will utilize Rose and Valverde's concept of problematizations accompanied with a history of fat to demonstrate the transformation of obesity from private bodily issue to a public target of governmental regulation.

In this Chapter, I will examine the history of North America's morally problematic relationship with the substance of fat. While I do not intend to go so far as to ultimately blame religion for the existing stigmatization of the obese, I will argue that the Christian Bible had a profound influence on moralizing the human body. By framing human fat as a transgression of spiritual devotion, the Bible had a particularly negative effect on bodies containing excess fat tissue. Furthermore, this stigmatization of obesity played an effective role in transforming the private issue of body fat into a problem requiring legal attention; thus subjecting the human body to the public agendas of modern governance.

\footnotetext{
${ }^{72}$ D. Greaney "King-Size Homer". Episode Number 135. The Simpsons. Fox Television. November 5 1995.
} 


\section{The History of Obesity}

In order to trace the transition of obesity from a private issue to a public issue, an historical approach must be taken to address the relationship between the government and obesity prior to regulation and after. Rather than frame the issue of obesity as one that has always been subject to legal regulation by the state, I will argue that the fat content of the human body has been transformed from a state of human physical size into a problematized issue requiring the governing of authority law. It is important to emphasize that the problematization of an issue such as obesity is simply the reframing of an existing unregulated issue, into a launching pad through which the government can impose regulation.

Early Christians feared that demons could be hiding within their food and might easily become ingested. Therefore, they believed the best way to diminish the gratification of eating, was to counter such pleasure with the disciplinary exercise of fasting. ${ }^{73}$ While the physical act of eating in Christianity contains an aspect of profound ritual mystery such as the ingestion of the body and blood of Christ, or the delivery of earthly sin in the form of Eve's consumed apple, this highly spiritualized relationship of food in the Bible is problematic. Balanced between spiritual nourishment and physical temptation; food is both a symbol of spirituality and immorality. ${ }^{74}$

The relationship between Christianity and obesity is best exemplified by Saint Paul in the Corinthians,

Food is meant for the stomach and the stomach for food, and God will destroy both one and the other...Do you not know that your bodies are members of Christ?... Or do you

\footnotetext{
${ }^{73}$ M. Miles, "Religion and Food: The Case of Eating Disorders" (1995) Vol. 63, No.1. Autumn 1995 Journal of the American Academy of Religion at 549-564.

${ }^{74} \mathrm{Ibid}$.at 550 .
} 
not know that your body is a temple of the holy spirit within you, which you have from God, and that you are not your own? For you were bought with a price; therefore glorify God in your body. ${ }^{75}$

According to the Bible one's body belongs to God, and any form of bodily abuse directly affects that relationship; thus extending personal ideas about self gratification into the greater moral realm of spiritual responsibility. Therefore, participating in bodily indulgences such as overeating that result in physical corpulence, can be easily construed as a direct form of spiritual depravity.

Central to the biblical immortality of overeating is desire. In Confessions X.31 Augustine alleged that human beings are configured by desire. ${ }^{76}$ According to Christian texts such as the Bible, it is when human beings let their identity become shaped by desire that their true devotion to God become obscured. Miles tells of how Augustine "complained that he struggled against the temptation of overeating, calling eating and drinking a 'dangerous kind of pleasure', one which he explicitly included in his prayer for continence.,"77

In the biblical moral hierarchy with spiritual devotion to God at the pinnacle, obesity represents a direct contradiction; a very earthly and obvious transgression with a strong devotion to food. Within the Bible, extreme body weight is considered a measure of spiritual failing. ${ }^{78}$ Moreover gluttony is depicted within the Bible as a central indicator of moral weakness: "Be not among the winebibbers, or among gluttonous eaters of meat;

\footnotetext{
${ }^{75} 1$ Corinthians. 6:13

${ }^{76}$ Confessions X.31

${ }^{77}$ Miles, 551.

${ }^{78}$ Kenneth Ferraro, "Firm Believers? Religion, Body Weight, And Well-Being" (March 1998) Vol. 39, No.

3. Review of Religious Research. 224-244.
} 
for the drunkard or the glutton will come to poverty."79

A historical connection between surplus human fat and moral corruption which endures into present day can be found in the recent scholarly discourse surrounding religion. Especially prevalent in recent Christian literature is the argument that religious practice can mitigate obesity. While the correlations between rates of obesity and religion have not been proven, religious scholars argue that there is a correlation between obesity and morality, with religion acting as a mitigating factor. The argument of many modern theologians is as follows: given the doctrine of many religions which emphasize the importance of bodily health, those who follow religious tradition would be more inclined to manifest the sacredness of their bodies through a healthy regimen of physical activity than their more secular counterparts. ${ }^{80}$ Regardless of the accuracy of the correlations between obesity and religious devoutness, the current connection between religion and obesity represents an ongoing wave of existing obesity moralizations created in biblical times which remain embedded within society.

In comparison to other Western societies, the United States is highly religious. ${ }^{81}$ This helps explain the ease and strength connecting health, governance and moralism. ${ }^{82}$ However, in order to connect the demoralizing effect of the Bible with that of primarily secular modern-day societies, I will draw upon Emile Durkheim's sociology of religion.

Durkheim argues that religion, morality and law function similarly to one another in modern society's law, religion and morality

are equally directed at the members of the same

\footnotetext{
${ }^{79}$ Proverbs 23: 20-21

${ }^{80}$ K..H. Kim, "Religion and Body Weight" (2003) International Journal of Obesity 27, at 469.

${ }^{81}$ Ibid

${ }^{82}$ P. Stearns, Fat in America. In C.E. Forth \& A. Carden-Coyne (Eds.). Cultures of the abdomen: Diet, digestion, and fat in the modern world (New York: Macmillan 2005) at 246.
} 
community, they are supported by sanctions which are sometimes identical and always analogous; finally, if any of them no matter what their kind, is violated, the same sentiments of anger and distrust are aroused in people's consciences. $^{83}$

It is because the law derives its legitimization from the moral and religious convictions of the society from within which it operates, that religion and morality are inherently embedded within the rationale of law. ${ }^{84}$

While Durkheim focuses upon the societal interconnectedness between law morality and religion, it is the fundamental interplay between society and religious morality that I would like to concentrate upon. Although modern Western societies have become increasingly secular, the moral influences derived from the Christian Bible are still present. Therefore, even though the Bible no longer prevails as society's fundamental moral compass, the moralizations or more specifically demoralizations presented within the texts of the Bible concerning obesity are entrenched within society. The effect of biblical influence is largely mirrored within contemporary society's stigmatization of obesity.

Rather than begin as an issue of state importance, obesity first became a medical concern in the 1500 's. ${ }^{85}$ As obesity was not linked with overeating, it was therefore initially not viewed as either immoral or a hindrance to state progress, and therefore was not utilized as an object from which to implement legislation.

\footnotetext{
${ }^{83}$ W. S. F., Pickering, ed. Durkheim on Religion: A Selection of Readings with Bibliographies. (London: Routledge \& Kegan Paul, 1975) at 19.

${ }^{84}$ E. Wallwork, "Durkheim's Early Sociology of Religion" (Autumn, 1985), Sociological Analysis, Vol. 46, No. 3. at 201-217.

${ }^{85}$ K.. Albala, "Weight Loss in the Age of Reason" In C.E. Forth \& A. Carden-Coyne (Eds.). Cultures of the abdomen: Diet, digestion, and fat in the modern world (New York: Macmillan 2005) at 171.
} 
In 1595, medical physician Thomas Erastus produced the first study on how and why fat accumulates on the human body, establishing that only sufficiently heated bodies can accumulate fat, concluding furthermore that when the body cools the fat inside will congeal. ${ }^{86}$ Drawing on the teachings of Erastus, early seventeenth century physicians believed that overeating did not result in weight gain, but that eating more than one could digest would result in total emaciation. More importantly, obesity was considered a natural bodily state of existence, with no negative ramifications to human health. ${ }^{87}$ Central to early obesity discourse was blood and it was an accepted medical fact that the bodies of the thin contain a higher amount of blood than fat bodies. ${ }^{88}$ Seventeenth century doctor Walter Charleton used this concept of less blood to argue that obese individuals eat less than their skinny counterparts and therefore contain fewer veins from which to nourish the body. ${ }^{89}$

In 1670, physician Johan Friedrich Held was the first individual to define obesity, insisting that a waistline measuring over three feet, with a full stomach, should be considered as technically obese. ${ }^{90}$ Held focused on the question of how and why some bodies attracted fat, and others did not; he believed the answer lay within the stomach. Held believed, "A lack of stomach acid would lead to faulty digestion, or fermentation in this case, and the crude oily parts of the food would accumulate in the body." 91 Rather than simply advise people to eat less, in order to fend off obesity, chemical remedies were administered to speed the passage of food through the body and prevent an

\footnotetext{
${ }^{86} \mathrm{Ibid}$.

${ }^{87} \mathrm{Ibid}$. at 172 .

${ }^{88} \mathrm{Ibid}$. at 173 .

${ }^{89} \mathrm{Ibid}$. at 173.

${ }^{90}$ Ibid at 175 .

${ }^{91}$ Ibid. at 174.
} 
accumulation of fat. ${ }^{92}$ Held claimed that the cause of obesity was the result of air that binds with various acids resulting in coagulation, which are then deposited within the body's pores. $^{93}$

It is not until the late seventeenth century that Karl Christian Leisner, a German doctor, drew an important parallel between corpulence and death; claiming that, obesity is not, as old physicians claimed, merely a neutral condition, but one that impedes all bodily functions and is itself a morbid state. It prevents proper movement of the body, constricts the veins, clogs the body's passages leading to clogs and putrefactions... fat is not merely the concretion of deposits in certain parts of the body, but throughout the whole. ${ }^{94}$

While the causes of obesity were never entirely clear to Leisner, he theorized that declining to indulge in excessive food and drink may have a positive effect. Due to what can be best described as an early dieting fad, Leisner experienced many of his patients dabbling in some dangerous and drastic weight loss solutions. As a result of his advice one woman died from overdosing on a chick peas boiled with salt, in an attempt to dry out her body and achieve thinness. Regardless of Leisner's studies even at the conclusion of his career he was left sceptical about whether or not a cure for obesity existed. ${ }^{95}$ As science progressed the connection between overeating and obesity was made. However, rather than remain strictly medicalized, state governments began to take a keen interest in the governance of obesity.

It was not until centuries later that the first instance of the state denouncement of obesity occurred during World War One. As corpulence challenged notions of the

\footnotetext{
${ }^{92} \mathrm{Ibid}$.

${ }^{93}$ Ibid. at 176.

${ }^{94} \mathrm{Ibid}$. at 177 .

${ }^{95}$ Ibid. at 177 .
} 
masculine body, Zweiniger-Bargielowska states that, "Excessive girth transgressed growing pressures toward bodily norms and the celebration of a muscular but slim male ideal body. Finally, by inviting ridicule, obesity conflicted with hegemonic masculinity...Obesity conflicted with masculine beauty ideals based on a Greek aesthetic. ${ }^{.96}$ Unlike present day norms where diet and body issues are viewed as a predominately female problem, obesity contradicted the male norms of nineteenth century British society and thus acted as visible force of emasculation. ${ }^{97}$

Moreover, the emergence of obesity can be linked with the growth of the middle class and its increasingly sedentary lifestyle. The inactive basis for obesity is often referred to as degeneration:

Between 1870s and 1930s ... rapid rates of urbanization, the development of suburbs, a rise of sedentary occupations, and the expansion of rail, urban, and motor transport [attributed to a growth in weight gain]. Living standards increased dramatically with rising real incomes and abundant food supplies. Growing access to cheaper food coincided with shorter working hours, less demanding work due to mechanization, and more sedentary jobs. ${ }^{98}$

During the First World War, the high rejection rates of recruited soldiers resulted in a habitual anxiety concerning the inadequate food consumption of the poor more importantly, a new concern was now directed at the over consumption from the middleclass. ${ }^{99}$ The comparison of the danger and seriousness of starvation with that of overeating is an example of how obesity was first noticed by the medical community.

\footnotetext{
${ }^{96}$ I. Zweiniger-Bargielowska." The Culture of the Abdomen: Obesity and Reducing in Britain, circa 19001939” (2005) Journal of British Studies, at 241.

${ }^{97}$ Ibid

${ }^{98} \mathrm{Ibid}$. at 245 .

${ }^{99} \mathrm{Ibid}$. at 246.
} 
However, it was not until the 1930's that obesity again became a target of government interests.

The main impetus behind the British government's first national attempt at curbing obesity was the need to utilize human bodies for wartime. Rather than excessive body weight remaining a private issue, excessive body fat became a transgression of national efficiency. As the author Ina Zweiniger-Bargielowska states, "a well managed body became integral to civic virtue. ${ }^{, 100}$ The hegemonic ideals of masculinity became embodied as a form of deviance in the obese man, resulting in the perception that in being overweight one was failing to fulfill the national agenda and was considered a bad citizen. ${ }^{101}$ A 1929 report by George Newman, Britain's chief medical officer, vocalized the state's interest in ending obesity, "to build a healthy race [is] one of the primary objects of government... a nation becomes physically strong and healthy if each individual so cultivates his own body and mind as to live at the top of physical, mental, and moral capacity." 102 In short, the government's want to mitigating obesity was based not on medical concern, but a need to recruit the male body for the purposes of war.

While this early government interest in obesity focuses on Britain, the culture of reducing body size in order to fulfill government policy can be viewed as an international phenomenon that was mirrored in North America as a response to the rise of the urban industrial society. ${ }^{103}$ Furthermore, the American contribution to obesity literature focused on the labelling and categorization of bodies from which to define common norms and

\footnotetext{
${ }^{100} \mathrm{Ibid}$. at 244 .

${ }^{101}$ J. Bourke, Dismembering the Male: men's bodies, Britain and the Great War (Chicago: University Of Chicago Press, 1996) at 107-119.

${ }^{102}$ I. Zweiniger-Bargielowska at 250.

${ }^{103}$ Ibid. at 243.
} 
ideals on the shape of the proper human bodily aesthetic. ${ }^{104}$ With the food rationing requirements of Second World War, the early actions taken to stop obesity were short lived. Both physicians and state governments set aside issues of weight loss to focus on more pressing wartime issues, such as maintaining medical rations for civilian health. ${ }^{105}$

However, the state and public interest on the governing of human bodies through the means of obesity did not disappear entirely. These same ideas of moralism and obligations of citizenship that made obesity an appealing target for regulation in the 1930's reappear within North America's changing food environment of the 1970's.

Much like the rising concern surrounding obesity in the 1930's, a secondary interest in obesity was again spurred by fundamental changes in work and diet. While these alterations in the North American eating habits were a catalyst for higher rates of obesity, they also effectively placed a historically unparalleled emphasis on surplus body weight. This increased attention thrust the otherwise private matter of body fat into the public spotlight of stigma, medicine, and eventually government regulation. The upsurge of corpulence in the United States during the 1980's can be attributed to the abundance and availability of food, coupled with the escalation of sedentary desk jobs and transportation improvements which reduced the need to walk. ${ }^{106}$

Ironically, despite an emergence of the immensely popular diet culture in the United States by the 1970 's, Americans began to get fat. ${ }^{107}$ A 1979 study found that on average, both genders experienced a weight increase of five pounds, while another report found Americans had gained an average two pounds each during the 1970's alone, with

\footnotetext{
${ }^{104} \mathrm{Ibid}$. at 244 .

${ }^{105} \mathrm{Ibid}$. at 272.

${ }^{106}$ P. Stearns, Fat in America. In C.E. Forth \& A. Carden-Coyne (Eds.). Cultures of the abdomen: Diet, digestion, and fat in the modern world (New York: Macmillan 2005). 240.

${ }^{107}$ Ibid. at 247.
} 
caloric intake increasing as much as six percent between 1950 and $1978{ }^{108}$ ZweinigerBargielowska's argument that an increasingly sedentary life style results in mass weight gain is mirrored by Stearns' analysis of the new weight trends of the 1970's. However, while industrialism did result in a greater amount of desk bound jobs, North American weight gain was compounded by increased television viewing, the popularization of the personal computer, home video gaming consoles, and finally the aggressive marketing techniques of fast food restaurants such as McDonald's. ${ }^{109}$

The inflation of North American rates of obesity beginning in the 1970's can be attributed to the changing food culture. The marketing of high caloric sodas and snack foods became more forceful, while cheap food meant that restaurant meal portions increased considerably. The 1980's saw a drastic change in domestic habits as many Americans began working longer hours, work pressures resulted in altered eating habits. Stearns provides an interesting observation,

It was at least revealing that most places of work began to install food outlets in each building, to facilitate the quick bite. Americans were becoming uncomfortable with work, or leisure, that did not have a food source within easy reach, a change which both reflected and encouraged the new weight trends. ${ }^{110}$

At home dietary change also resulted in more people ordering takeout from restaurants, or consuming pre-packaged foods; often on the run. ${ }^{111}$ Increasingly, more children were left to their own devices after school, providing an unsupervised snack time, with parental guilt for being absent often expressing itself in the provision of snack

\footnotetext{
${ }^{108} \mathrm{Ibid}$.

${ }^{109} \mathrm{Ibid}$. at 250 .

${ }^{110} \mathrm{Ibid}$. at 252 .

${ }^{111} \mathrm{Ibid}$. at 251 .
} 
foods. ${ }^{112}$ Additionally while such snack foods were often advertized as aiding in health or energy levels, many of the individually packaged foods were simply high caloric foods in disguise as a healthy alternative. ${ }^{113}$

The multitude of factors that contributed to North America's convenience based food environment can be interpreted as a direct cause of an increase in North American rates of obesity. Furthermore the correlation between the rise of obesity and the recent vigorous legislative campaign is undeniable. It is because of the historical stigmatization of obesity that any increase in the demographic of obese citizens would rationally be met with social opposition.

\section{The Problematization of Fat}

Due to the nature of fat's existence within the human body, in order to govern fat to impede obesity, North Americans must be willing open themselves up to outside authorities; as a result obesity does not easily open itself up to outside governance. Obesity originated as purely a medical concern that later became accompanied by a publically held moral stigma. It is these same publically held moral stigmas that eventually became utilized by modern governments as a means of transforming obesity as an individual problem to one of state importance. It is through Rose and Valverde's concept of problematization that the relationship between law and fat is firmed up.

In their article "Governed By Law?" Nikolas Rose and Mariana Valverde analyze the relationship between diverse instruments of law and the ability of norms to substituted for the power of law. ${ }^{114}$ Rose and Valverde argue that law is peripheral to governance; establishing that what becomes regulated does not originate within law, but

\footnotetext{
${ }^{112}$ Ibid.

${ }^{113}$ Ibid.

${ }^{114}$ N. Rose and M. Valverde, “Governed By Law?" (1998) Social \& Legal Studies, Vol. 7, at 541.
} 
stems from problems or problematizations that need attention. Rather than the law denouncing an existing problem, the authors explore the ways that a particular problem such as obesity, emerges as a target for law and regulation.

Central to Rose and Valverde's argument is the existence of social law the alternative to the traditional rule based judicial law from which Rose and Velvarde claim we can better understand forms of governance. Rather than impose rules on society, social law derives its strength from the power of norms. ${ }^{115}$ The operational differences between a rule and a norm are outlined as follows. While a rule is a code of behaviour developed externally which is then applied to the social order by the formal ruling body, a norm emerges from society as a common standard from which society affirms its collective values. ${ }^{116}$

Societal norms are dichotomous as they act to affirm the commonality of human populations, while exacerbating the differences of those who do not conform. As argued by the authors, "normative government and the social laws that it generates actually institute society itself: the norm is a means of producing social law, a law constituted with reference to the particular society it claims to regulate and not with respect to a set of universal principles." 117 Therefore, if the current societal norm of North American society is centered around remaining skinny for the good of the state, obesity represents a transgression of societal norms from which law is used as a remedy.

Rather than contend that judicial law has been completely supplanted by social law, Rose and Valverde claim that the concept of a monolithically regulatory matrix of law

\footnotetext{
${ }^{115}$ Ibid at 544 .

${ }^{116}$ Ibid.

${ }^{117} \mathrm{Ibid}$ at 545 .
} 
exists only as a figment of the legal discipline; in other words The Law does not exist. ${ }^{118}$ In eliminating the unified concept of law, Rose and Valverde fill the void with problematizations, a concept which they tersely define as problems requiring attention. The following passage outlines the author's approach to challenging conventional notions of legal scholarship;

The intellectual premises and analytical methods of legal studies tend to presuppose that objects and problems form within the workings of the law itself. But in order to analyze the ways in which problems form at the intersection of legal and extra-legal discourses, practices and institutions, it is necessary to de-centre ${ }^{119}$ law from the outset. ${ }^{120}$

In focusing not on how law regulates, but the process by which something emerges as a target of governmental regulatory interest, Rose and Valverde are successful in recasting law as subsidiary to what becomes problematized and ultimately governed. For Rose and Valverde, law does not represent the loci of their focus, but it simply a culmination of governable interest on a particular problem. Their approach to conducting an analysis of problematizations is set out in the article Governed By Law? To understand how problems become governable what must be investigated is the location from which problems emerge, as well as the identification of those who define the problem as requiring government attention. ${ }^{121}$

Rose and Valverde's attention to the emergence of social problems into state created legislation exemplifies the means with which morality and its resulting stigmas become transformed into legislation. Their bottom up methodology views the creation of

\footnotetext{
${ }^{118}$ Ibid.

${ }^{119}$ The removal law from the initial analysis of a problem in order to focus on the non-legal issues that eventually become legalized.

${ }^{120}$ Rose and Valverde at 545.

${ }^{121}$ Ibid. at 546.
} 
formal law as the outcome of moral transgressions from which social norms regulate and ultimately becomes attached to legislation. In arguing that law originates from problematizations the focus becomes directed at the non-legal stigmas and governing agents that existed prior to the creation of law which effectively result in the problematization of issues such as obesity. Furthermore, legal ramifications are created based upon the actions of the diverse forms of governing agents that exist within the spectrum of moral regulation. It is within the following chapters that moral panic and Foucaultian forms of regulation will provide a means from which problematizations are transformed into a regulatory strategy from which the entire North American population becomes a governable commodity.

As shown by the medical interest surrounding obesity in the 1500 's, the first step of the problematization of obesity was its medicalization. It was only after the medical community took an interest in the effects of surplus fat within the human body that government then saw a means of utilizing a health based approach from which to implement obesity based wartime regulation. As put forth by Rose, a subject becomes medicalized "when a problem is created or annexed, in whole or part by the apparatus of medicine."122 The medicalization of obesity represents the authority of science claiming the body as a means from which to institute governance in order to promote collective health. ${ }^{123}$ Furthermore, obesity's early medicalization is the first prominent shift from fat being an individual private concern to one of greater importance. However, rather than remain a medical issue, obesity became further problematized by state means. As the North American rates of obesity increased more medical attention became devoted to the

\footnotetext{
${ }^{122}$ N. Rose, "Beyond Medicine" (2007) Vol. 369. The Lancet Journal, at 700.

${ }^{123} \mathrm{Ibid}$. at 700.
} 
issue of obesity. This medical interest was accompanied by the state's desire to become involved in the governing of obese bodies in order to save economic resources.

Rose and Valverde's analysis which focuses not on law, but on the problems that require the governance of law, is demonstrated within the emergence and eventual regulation of obesity. For Rose and Valverde law exists only within the legal discipline. ${ }^{124}$ Rather than hold law accountable for governance, law in the regulatory sense is replaced with the governing power of norms. Therefore, instead of originating within the law as a problem necessitating governance, human fat which predominantly functions to insulate the human body, would presumably fall outside the spectrum of government regulation. However, a product of the biblical moralization of fat is the societal stigma of obesity which continues to exist within modern society. A result of this persisting stigma is the societal norm of hostility to those who are obese. Therefore, rather than regulate obesity through legal means, the state's governing power of obesity is achieved through the exploitation of societal norms which deem excess fat a moral transgression.

As Rose and Valverde argue that the strength of social law is derived from the power of norms, ${ }^{125}$ obesity represents physical noncompliance with the collective values of society. Therefore, the existences of external rules are not necessary as societal norms provide an incentive for problematizing those who fall outside of the accepted social ideal of fat content.

The historical presence of the stigma of obesity within North American society establishes that the problematization of obesity did not occur as a result of law, but was

\footnotetext{
${ }^{124}$ Rose and Valverde at 546.

${ }^{125} \mathrm{Ibid}$. at 544.
} 
simply adopted by governments in order to formalize a specific regulatory approach. It is because of the bible's moralization of fat that the non-formal problematization of obesity occurred first and was followed by a framework of formal regulation based upon on the existing social perception which condemned obesity.

While the existence of social stigmas motivated the problematization of obesity, the medicalization of surplus fat also contained important implications for the problematization and governance of obesity. Prior to the medicalization of obesity, the ramifications of being overly corpulent were limited to non-formal means of governance. However, when the medical community defined obesity as a problem, human fat became subject to medical governance. The ability of medicine to penetrate the flesh of humans and deem the fat naturally produced within the body problematic, gave governments access into an area which was previously unaffected by government policy, the realm of body fat. If obesity had not been medicalized prior to the governments' problematization of fat, even the historical existence of social stigma would not have made the implementation obesity based governance feasible. As the medicalization of obesity asserted that bodily governance was part of a collective health agenda, this medical agenda was then adopted by North American governments in order to implement a regulatory strategy from which to govern North American bodies. However, unlike the medicalization of obesity, government problematization through regulatory means was motivated not by human health, but by economic desire.

As having excessive amounts of fat within one's body originally fell outside of the regulatory attention of the state, it is important to understand why the state felt became motivated to regulate fat. While government interest in obesity began in the 1930's, it is 
the modern changes in North American diet and lifestyle beginning in the 1970's that mark the emergence of obesity as a target for regulation. The increase in obese North Americans raised the cost of health care as well as subtracted from the available workforce; these costs which are estimated to be in excess of a billion dollars ${ }^{126}$ are the catalyst for the North American government's effective problematization of body fat. Furthermore, it is because of the biblical moralization of obesity that official governing bodies such as North American governments are able to gain public acceptance for their regulatory access into the human body. Combined with the ancient moralization of obesity, which sufficiently demonizes human fat as a characteristic of gluttony and the need to conserve economic resources, a modern societal desire for obesity governance is created.

It is through a series of problematizations that obesity became transformed from a private issue to a legal one. However, whereas the problematization of obesity made it an available target for government regulation, it simply affixed law to the internal body fat of the North American population. What the resulting problematization of obesity cannot explain is a proper regulatory strategy for the widespread governance of the entire North American populace.

It is within the following chapter that the problematization of obesity becomes attached to the larger social movement of a moral panic. By reclassifying obesity as a legal problem requiring governance, Canadian and American governments are able to capitalize on the problematization of obesity by means of a moral panic. Furthermore, as will be addressed within the subsequent chapter, it is by increasing the public's

\footnotetext{
${ }^{126 ، " F}$ as in Fat: How Obesity Policies are Failing in America 2005" Trust for America's Health. August 2005, www.healthyamericans.org.
} 
perception of the problem presented by obesity that North American governments benefit from the resulting public anxiety, and are thus able to implement extensive methods of human governance aimed at the citizens of North America. 


\section{Chapter III: Moral Panic and the Extension of Obesity Governance}

Over a quarter of American college students claim that getting fat is the worst thing that can ever happen to a person. ${ }^{127}$ This almost apocalyptic vision of fatness is shared by the greater North American population and is visibly reinforced by media outlets such as celebrity tabloids. With headlines such as "How Brit got thin: 26 pounds in one month" ${ }^{\text {"128 }}$ or "Jessica's agony, bullied for her weight: how she was tortured by food" 129 tabloid fodder capitalizes on the weight battles of the predominately thin and attractive with a sensationalism and seriousness usually reserved for catastrophic events causing human causalities.

While law became attached to obesity through a serious of problematizations, what is still lacking is a practical regulatory strategy from which governance can be implemented. As an effect of the problematization of obesity stemming from primarily moral reasons, it is not surprising that what has occurred within North America during the last fifteen years can be considered a moral panic. It is from this moral panic that governing techniques can be expanded to motivate the creation and implementation of widespread forms of human governance aimed at both the obese and the non-obese members of North American society.

Moral panic theory provides a lens through which fear becomes a tool that justifies obesity regulation as necessary to public welfare. By capitalizing on the North American population's already morally problematic relationship with corpulence, the American and Canadian governments create concern around the issue of obesity. This moral panic provides a means through which obesity regulation can be successfully

\footnotetext{
${ }^{127}$ Rebecca Puhl and Kelly D. Brownell, "Bias, Discrimination, and Obesity" (2001) 9 Obesity Res. at 788.

${ }^{128}$ US Weekly, Issue 611. October 30, 2006.

${ }^{129}$ US Weekly, Issue 731. February 16, 2009.
} 
implemented on non-obese society under the guise of a preventative measure.

Furthermore, through a moral panic the scope of regulation is expanded to include both problematic and potentially problematic individuals.

In addition to accounting for an increase in and expansion of available regulatory targets, moral panic theory provides an explanation as to why non-obese individuals are being subject to anti-obesity measures such as the banning of trans-fats, and punitive taxes on high caloric foods. It is through the endorsement of a moral panic aimed at the obese that governments are able to capitalize on and further generate a social anxiety about being fat in order to create a pressing need for regulation. By sustaining a panicked social environment, it becomes easy to implement regulation aimed not just at the obese but everyone. Furthermore, by expanding the scope of regulation to include the entire North American population regulatory precautions can be taken to prevent the non-obese from becoming obese, thus increasing the North American population's desire for obesity governance.

In order to demonstrate the process through which obesity has become encompassed within a moral panic, I will first provide an in depth look at Stanley Cohen's moral panic theory followed by an application to the present day social circumstances surrounding obesity. However, rather than simply establish the societal reaction to obesity as one of panic I will utilize the creation of a moral panic as a tool from which social anxiety transitions the problematized issue of obesity from simply a legal issue to one which involves a multifaceted array of governing strategies all aimed at reducing the size of the physical human body. 
Furthermore, I will demonstrate that as result of a moral panic the public becomes increasingly receptive to a large number of diverse forms of regulation created with a singular goal, mitigating the physical size of the North American public in order to save health care money, thus exemplifying governmentality.

\section{Stanley Cohen's Moral Panic Theory}

The concept of moral panic was launched into the popular lexicon by Stanley Cohen in his 1973 book, Folk Devils and Moral Panics. ${ }^{130}$ Cohen's conceptualization of moral panic theory constructs a means through which concepts of deviance, collective behaviour, social movements, and mass communication correlate to explain public reaction to a perceived threat. ${ }^{131}$ According to Cohen moral panics are a reoccurring condition that arises when: "a condition, episode, person or group of persons emerges to become defined as a threat to societal values and interests." 132 While the subject of a moral panic can be something eccentric (such as the as fear of Satanists kidnapping and breeding children that plagued parts of the United States in the early 1980's), ${ }^{133}$ previously existing and non-threatening groups can also become sensationalized into becoming perceived as a menace.

The indicators that characterize a moral panic can be defined by five criteria: concern, hostility, consensus, disproportionality, and volatility. ${ }^{134}$ The first indicator of a moral panic lies within an increased level of concern relating to the actions of a certain group and the perceived risk of danger that their behaviour causes for the rest of the

\footnotetext{
${ }^{130}$ S. Cohen, Folk Devils and Moral Panics (London: MacGibbon and Kee, 1972)

${ }^{131}$ E. Goode and N. Ben-Yehuda, Moral Panics the Social Construction of Deviance (Oxford: Blackwell Publishing, 1994) at 29

${ }^{132}$ Cohen, Folk Devils and Moral Panics (London: MacGibbon and Kee, 1972) at 9.

${ }^{133}$ Goode and Ben-Yehuda at 57.

${ }^{134}$ Ibid. at 33 .
} 
society. This concern must be accompanied by hostility; thus producing a division between $u s$ and them, and creating folk devils out of a now villianized portion of society.

As moral panics vary in size there is no strict requirement for a uniform consensus of concern against the perceived threat. ${ }^{135}$ However, there must be some minimal form of consensus in either parts of society, or society as a whole that there is a real threat being caused by the misconduct of an identifiable societal group. ${ }^{136}$ As the term moral panic suggests, the fourth requirement of disproportionality conveys that the majority of preventative measures taken in response to the perceived harm far outweighs the actual threat. $^{137}$

The final indicator of a moral panic is volatility. Even though moral panics may reappear from time to time and often become dormant, they are very explosive in that they erupt suddenly causing a wake of promised social changes only to disappear. The high amount of hostility generated during a moral panic is hard to sustain over a long period of time, and is thus comparable to the all too familiar frenzied but short-lived fashion fad. ${ }^{138}$

Adopting Becker's approach to transactional deviance Cohen is at pains to establish that deviance is not established by the actor; deviance is created by society... Social groups create deviance by making the rules whose infraction constitutes deviance and by applying those rules to particular persons and labelling them as outsiders... The deviant is one whom the label has successfully been applied. ${ }^{139}$

\footnotetext{
${ }^{135} \mathrm{Ibid}$. at 34 .

${ }^{136}$ Ibid.

${ }^{137} \mathrm{Ibid}$. at 6.

${ }^{138} \mathrm{Ibid}$. at 39.

${ }^{139}$ Cohen at 13.
} 
In short, deviance is not a trait inherent within the individual, but a label given by society. The transactional approach does not imply deviant roles such as being a folk devil, are simply stamped on innocent persons to fulfill a societal gap..$^{140}$

In a moral panic the reaction of fear and the need for action are disproportionate to any real and pressing danger facing society. As a result of this discrepancy, some members of society become perceived as an immediate threat, and form the loci of the moral panic; they are characterized by what Cohen refers to as folk devils. Societies erect folk devils in order to provide a stark reminder to its members of the importance of upholding social rules and as a way of clearly indentifying those who defy such conventions. ${ }^{141}$ The labelling of folk devils as societal outcasts is an understatement; the creation of folk devils involves reducing all favourable characteristics possessed by an individual or group with unabashed negativity and vice. Furthermore, the creation of folk devils involves a full scale demonology of character combined with impending doom if action is not taken to correct such moral decay. ${ }^{142}$

Fundamental to Cohen's moral panic theory is the role of the media in the creation and sensationalization of folk devils. ${ }^{143}$ In Folk Devils and Moral Panics, Cohen focuses on the interactions between two youth counter culture groups, the mods and the rockers. Central to Cohen's analysis of panic generated by the two opposing groups is the media's exaggeration of events and their projection onto the public. The actual events that transpired between the mods and the rockers on the beaches of Clacton in 1964 could be considered at best, a minor ruckus. However, the British media's headlines were fraught

\footnotetext{
${ }^{140} \mathrm{Ibid}$. at 14 .

${ }^{141} \mathrm{Ibid}$. at 10.

${ }^{142}$ Goode and Ben-Yehuda at 28.

${ }^{143} \mathrm{Ibid}$. at 25.
} 
with the sensationalism claiming that the formerly quiet beachside town had been rampaged by an onslaught of youths resulting in orgies of destructions, riots, and mob violence. ${ }^{144}$ The general consensus of the media concerning the events at Clacton was that the main perpetrators were youth gangs from London, storming the seaside town on motor scooters and motorcycles in order to cause mass destruction. ${ }^{145}$ The reality of the situation is as follows, the gangs from London were loosely assembled locals, on foot, and visiting Clacton simply to witness any trouble that did result. ${ }^{146}$

According to Cohen, the dissemination of news in industrial societies is inherently distorted. "That is, [news] arrives already processed by the mass media and this means that the information has been subject to alternative definitions of what constitutes 'news' and how it should be gathered and presented." ${ }^{147}$ As exemplified by the events of Clacton Beach, information being overly sensationalized and disseminated by the media can result in a factually unfounded societal uproar. Cohen claims that it is the media's exaggeration of the events, followed by their widespread broadcast into the public realm that results in the creation of folk devils. Integral to the moral panic is that no forms of deviance have been factually substantiated, nor does any form of actual threat have to be present. As stated by Cohen, the moral panic and creation of folk devils is simply the result of the media's embellishments of fact. It is through the dramatization of headlines that newsworthy stories are created in order to sell more papers. ${ }^{148}$

In order to further analyze the reaction of the media to the so called confrontation between the mods and the rockers on Clacton beach, Cohen created three headings,

\footnotetext{
${ }^{144}$ Cohen at 31.

${ }^{145} \mathrm{Ibid}$. at 33 .

${ }^{146}$ Ibid.

${ }^{147}$ Ibid. at 16.

${ }^{148}$ Ibid. at 44 .
} 
"Exaggeration and Distortion, Prediction, and Symbolization". ${ }^{149}$ In the Exaggeration and Distortion section Cohen focused on the media's over reporting. In his analysis of the various media accounts of Clacton beach, Cohen found that the media were prone to exaggerate the seriousness of each act,

Such distortion took pace primarily in terms of the mode and style of presentation characteristic of most crime reporting: the sensational headlines, the melodramatic vocabulary and the deliberate heightening of those elements in the story considered as news. The regular use of phrases such as 'riot', 'orgy of destruction', 'battle', 'attack', 'siege', ... and 'screaming mob' left an image of a besieged town from which innocent holiday makers were fleeing to escape a marauding mob. ${ }^{150}$

The news reported was a stark contrast to the reality of the situation, as on the day in question Monday, May 18, 1964 the beaches were deserted, caused not by a fear of youth gangs, but simply a threat of rain. In fact, according to Cohen the events at Clacton beach received the frenzied attention of the news media simply because there was an absence of newsworthy activity both locally and internationally.

Another source of media misrepresentation lay within the repetition of factually accurate stories. While the facts themselves would be correct, they would be presented in an altered context giving the appearance of deviance and therefore adding to creation of moral panic. ${ }^{151}$

Cohen's second category Prediction is the assumption that the events that transpired would inevitably occur again, the only question was where and when the mods and rockers would strike next. ${ }^{152}$ Cohen makes a clever comparison between the public

\footnotetext{
${ }^{149} \mathrm{Ibid}$. at 31 .

${ }^{150} \mathrm{Ibid}$. at 31 .

${ }^{151} \mathrm{Ibid}$. at 33 .

${ }^{152} \mathrm{Ibid}$. at 38 .
} 
reaction stemming from deviance and natural disasters stating that "Unlike the case of natural disasters where the absence of predictions can be disastrous, with social phenomena such as deviance, it is the presence of predictions that can be disastrous". ${ }^{153}$ It is from reporting predictions that the media are reporting non-events that will undoubtedly impact the publics' perception of threat while confirming expectations and ignoring those which are contradictory. ${ }^{154}$

What results from the media's exaggeration and distortion of events is the symbolization of words to portray complex ideas and emotions. ${ }^{155}$ Formerly neutral words such as mod, rocker, and Clacton become a catalyst for negative public reaction. Cohen states that symbolization consists of three processes: "a word (mod) becomes symbolic of a certain status (delinquent or deviant); objects (hairstyle, clothing) symbolize the word: and the objects themselves become symbolic of the status (and the emotions attached to the status)" ${ }^{156}$ A direct result of the media's distortion of events, symbolization is what helps to promote a moral panic. In May 1964 a British newspaper reported a headline of 'Terror Comes to English Resorts. Mutilated Mod Dead In Park'157 The actual events were that transpired was a man between the ages of twenty-one and twenty-five was found dead in a park, a day prior to the events at Clacton. ${ }^{158}$

While Cohen predominantly refers to the print media such as newspapers, symbolization and exaggeration and distortion is also increased via photographs and televised news reports. ${ }^{159}$ Though photographic media may appear more objective,

\footnotetext{
${ }^{153} \mathrm{Ibid}$. at 39.

${ }^{154} \mathrm{Ibid}$.

${ }^{155} \mathrm{Ibid}$. at 40

${ }^{156} \mathrm{Ibid}$.

${ }^{157} \mathrm{Ibid}$. at 42.

${ }^{158}$ Ibid.

${ }^{159}$ Ibid. at 43 .
} 
photographs are able to be distorted through the capturing of images which convey symbols that sharpen the public's perception of threat. Cohen states that "through closeups and a particular style of commentary ... television structured the whole event to convey emotions non-existent to the participants. This affect explains why many spectators at the Mods and Rockers events found them slight let-down after the mass media publicity" 160

Cohen refers to the ability of the media to hype the deviant of harmless acts as deviancy amplification. It is by focusing attention on a series of unlawful or morally denounced acts that the media is able create a pattern from which an innocuous singular act appears more serious and increasingly common. ${ }^{161}$

Although Cohen holds the media culpable for the causation of the moral panics, the media cannot create a moral panic out of a vacuum; there must be other agents. According to Cohen's view, a moral panic begins with the media and cannot be sustained without the public's anxiety. In order for the media to generate a campaign which grips the moral psyche of the public there must be public concern. If the media attempts to develop hysteria over an issue with which the public holds a more sophisticated view, or an issue which does not manufacture public concern then a moral panic will not be created. ${ }^{162}$ Regardless of what the media report on, the catalyst for a moral panic exists within the social consciousness.

Counter to the creation of the moral panic, and equally as important is the response; the collective desire that 'something must be done'. At the centre of this reaction are the

\footnotetext{
${ }^{160}$ Ibid. at 43.

$161 \mathrm{Ibid}$. at 200.

${ }^{162}$ Goode and Ben-Yehuda at 26.
} 
agents of social control: law enforcement officers, politicians and legislators, and action groups. ${ }^{163}$

As discussed in the previous chapter, agents of moral governance extend beyond traditional means and encompass all those who discourage a form of behaviour. In taking into account the importance of norm oriented movements, Cohen stresses the social significance of action groups and their role in reaffirming society's moral enterprise in the face of transgression. While the lasting power of social changes brought about by a moral panic is inherently short-term, the importance of a moral panic lies not within its legislative changes, but in the ability to validate the creation of new forms of legislation that would otherwise remain unjustifiable. Much like Cohen's study of the events that occurred between the mods and rockers at Clacton Beach exemplified, it is when embroiled in a moral panic that society can create folk devils and thus generate new forms of control with which to halt the onslaught of the perceived threat.

\section{The Moral Panic of Obesity}

In order to demonstrate the modern relationship between moral panic and obesity, one must understand the ways in which obesity transcends the standard classification of a social problem. The multiple definitions of a social problem stem from the objectivist ${ }^{164}$ view, ${ }^{165}$ to the constructivist idea. ${ }^{166}$ While the definition of a moral panic overlies that of

\footnotetext{
${ }^{163}$ Ibid. at 28.

${ }^{164}$ A social problem is anything that has the potential to harm or deteriorate the quality of human life

165 J. Manis, "The concept of social problems: vox populi and sociological analysis" (1974) Vol. 21 Winter. Social Problems at 305-315.

${ }^{166}$ Constructivist view is that social problems are simply constructed by the human mind.
}

M. Spector, and J. Kitsuse. "Social Problems: a re-formulation." (1973) Vol. 21 Fall. Social Problems at 145-59 
a social problem, ${ }^{167}$ moral panics have distinct differences; the most important being the existence of folk devils.

As the creation of folk devils involves the stripping of favourable characteristics leaving only a personification of evil, this process is created by society in order to erect an obvious reminder about what type of person its member should avoid becoming. ${ }^{168}$ At the core of every moral panic is the need to "identify, denounce, and attempt to root out folk devils" ${ }^{169}$ this same pattern is mirrored in North America's current response to obesity.

The transformation of overweight North Americans into folk devils is exemplified by the disgust, fear and blame that are harboured by greater society against the obese for their immoral lifestyle, which is perceived by many as threatening to destroy the health care system and furthering societal degeneration. Furthermore, while obesity counters societal conventions of self-control, personal betterment, industriousness and body aesthetics, the obese are an easy identifiable group, thus making them an obvious target for becoming a folk devil. The connection between one's physical size and the contradictions it poses to North American society is one of rationalized hatred. It is the overwhelming public perception that obese individuals pose a risk to the rest of society through their consumption of both health and economic resources that makes obese citizens folk devils, leaving less money and health care resources for those who are nonobese and perceive themselves as therefore more deserving.

${ }^{167}$ Much like how problematizations are utilized as means of governing problems through legalization, social problems are also constructs of society. Both social problems and problematizations are applied to previously unproblematic societal issues, in order to create a governable issue. Furthermore, similarly to the creation of problematizations, social problems are often created by those groups who are likely to benefit from the creation of a new problem.

${ }^{168}$ Cohen at 40.

${ }^{169}$ Goode and Ben-Yehuda at 29. 
It is believed that as a result of obesity within a generation half of Americans will become diabetic, effectively crushing the United States' healthcare system. ${ }^{170}$ It is this impending financial doom attached to obesity that is fundamental to the creation of the overweight as a folk devil. Rather than view the obese as ordinary citizens who are simply larger than most, overweight people become demonized as social others whose behaviour threatens to drastically lower the North American standard of living. Furthermore, 'the something must be done' to stop this behaviour attitude is echoed in countless government and medical reports such as the Canadian Public Policy's report Measuring Obesity in Young Children, which seeks to prevent obesity in children via policy decisions. $^{171}$

What makes the excessively corpulent a classic folk devil is not what obesity is, but what obesity represents: “Fat symbolizes poverty, non-whiteness, loss of social and economic status, lack of self discipline and the out over control over-consumption it leads to and loss of control in general." ${ }^{, 172}$ By creating a scapegoat out of obese citizens' governments absolve themselves of blame, denying among other things that there is nothing fundamentally flawed in the health care system, nor is there anything wrong with North American classism or economics. ${ }^{173}$ By creating a folk devil out of the obese, legislators are able to capitalize upon the heightened concern rippling throughout society

${ }^{170}$ P. Campos, "The The Legalization of Fat: Law, Science, and the Construction of a Moral Panic" (March 3, 2006). Bepress Legal Series. Working Paper at 96.

${ }^{171}$ S. Phillips, "Measuring Obesity in Young Children" (Dec. 2004) Canadian Public Policy. Vol 30 No. 4 at 349-364.

${ }^{172}$ Campos at 97.

${ }^{173}$ Compos at 98. 
and over compensate for the problem through excess governance ${ }^{174}$ extending from the obese, to the non-obese.

In order to demonstrate that North America is currently under the grip of a fat fuelled moral panic the criteria adapted by Goode and Ben-Yehuda from Stanley Cohen's Folk Devils and Moral Panics measuring concern, hostility, consensus, disproportionality, and volatility will be applied to the modern day obesity scare.

Beginning in the 1980's there has been an unprecedented increase in the level of concern surrounding not just obesity as a medical issue, but the consequences obesity presents for the rest of society. ${ }^{175}$ Stemming from both the media and legislatures the recent steep escalation of anxiety can be measured from the output of articles and attempted laws aimed at obesity. In 2002 a record seventy two bills were created to target obesity within the United States, ${ }^{176}$ "that number more than doubled to 170 in 2003 , and doubled again to more than 350 in 2004."177 Furthermore, since the 1980's the media's coverage of obesity has risen from sixty articles a year to seven thousand in $2003 .{ }^{178}$

The second criterion for a moral panic is an increase of hostility towards the group in question, in this case the obese. ${ }^{179}$ Such hostility can be measured in the collective designation of the obese as the enemy as well as the process through which obese individuals have become folk devils. As obesity is historically a morally charged topic it has always been met with feelings of resentment and disapproval. However, since the

\footnotetext{
${ }^{174}$ Excess governance may include increased anti-fat legislations such as fat taxes which effect both obese and non-obese consumers, as well as elementary schools weighing children and reporting the results to the parents and state governments .

${ }^{175}$ Campos at 33.

${ }^{176}$ This was done at the State level within the U.S.

${ }^{177} \mathrm{lbid}$ at 20.

${ }^{178}$ A. Saguy and K. Riley, "Framing Contests Over Obesity" (2005) 30 Journal of Health Politics Policy \& Law at 869.

${ }^{179}$ Goode and Ben-Yehuda at 33.
} 
1980's an increase in North American rates of obesity has intensified existing negative attitudes into an outlook that can be best described as hostile. The rise in hostility may be attributed to the perception that the obese are both a threat to society and are ultimately responsible for their condition.

Societal hostility towards the obese can be demonstrated through laws such as the pre-mentioned Commonsense Consumption Act. ${ }^{180}$ Rather than examining alternative avenues of blame such as socioeconomic factors, ${ }^{181}$ advertising, ${ }^{182}$ or infrastructure, ${ }^{183}$ such laws establish the overweight individual as the offender.

Another way from which insight into the societal hostility towards obesity can be gained is by looking at the comments left on media such as internet news forums.

Recently the issue of obese individuals requiring an extra seat whilst flying commercial airlines has been resolved by the Supreme Court of Canada who ruled that rather than forcing those whose size necessitated two seats to pay for an extra ticket, a one person one fare rule applied. ${ }^{184}$ The response from those who commented on the news story in a $\mathrm{CBC}$ online forum consisted of the following statements,

You may not like what I am saying but you know damn well that fat people have only themselves to blame for being fat...I hate sharing my seat with some fat person. Either charge them for two seats or charge me for half a seat...We have to start taking responsibility for our lifestyle whether we are overweight, alcoholic, gamble, or drug user, prescription or other drugs... We have made people believe that nothing is their fault and just expect the

\footnotetext{
${ }^{180}$ Commonsense Consumption Act of 2005, H.R. 554, $109^{\mathrm{TH}}$ Cong.

181 J. Cawley, "The Impact of Obesity on Wages" (2004) The Journal of Human Resources . Vol 39. No. 2 at $451-474$.

182، The Elephant in the Room: Evolution Behavioralism, and Counteradvertising in the Coming War Against Obesity" (Feb., 2003) Harvard Law Review vol. 116. No. 41166.

183 "Obesity in Canada Identifying Policy Priorities", INMD Publications. Ottawa Ontario June 23. http://secure.cihi.ca/cihiweb/products/CPHI_proceed e.pdf at 5.

${ }^{184}$ CBC News, "Your View: Should Airlines Charge Obese Flyers for Second Seats?"

http://www.cbc.ca/news/yourview/2009/04/should_airlines_charge_obese_f_1.html, April 172009.
} 
government to pick-up the tab, which really is the taxpayer. Come on you guys take control of your life, you might need counselling but if it helps get you on track just do it. ${ }^{185}$

The majority of the comments left was overwhelmingly hostile and focused on the culpability of the obese for their behaviour. Furthermore, the general consensus among the forum posters was that the irresponsible and unchecked gluttonous behaviour of the obese threatened to damage society through their mass consumption of health care resources; thus articulating the reasons that the obese are now considered folk devils.

As moral panics come in different sizes and require different amounts of societal consensus, ${ }^{186}$ the current moral panic of obesity is one fuelled by an international public concern. The global consensus that the obese represent an identifiable threat is manifested within the various national and international strategies formulated to impede the growth of obesity. Countries throughout Europe, Canada, and the United States have all produced multitudes of reports aimed at reducing obesity in order to conserve healthcare dollars through the reduction of their populations' weight. ${ }^{187}$ Some of the major initiatives include the European International Association for the Study of Obesity, the International Obesity Taskforce, as well as the North American Association for the Study of Obesity.

Inherent within the meaning of the term moral panic is the implication that the public concern far outweighs any potential harm. ${ }^{188}$ It is the disparity between the actual harm caused by obesity and the heightened perception of harm spawned from public anxiety that results in disproportionality. Richard Carmona America's Surgeon General

\footnotetext{
${ }^{185}$ Ibid.

${ }^{186}$ Cohen at 75.

${ }^{187}$ Goode and Ben-Yehuda at 37.

${ }^{188}$ Ibid. at 19.
} 
proclaimed obesity as a "terror within [and] a threat every bit as real to America as weapons of mass destruction." 189 In situating obesity alongside America's Iraq war, the Surgeon General's statement implies that by "being overweight or obese"190 one can be equated to a global terrorist; transforming what used to be a private issue into a matter of national security. It is through extreme government statements such as the one posed by Carmona that obesity becomes viewed as deceptively threatening. This false sense of alarm increases the public's need for safeguards against the obese, resulting in an increase of anti-obesity governance.

A recent study which examined the relationship between mortality and excess weight, indicated that a higher percentage of average weight American's die prematurely than Americans who are overweight and obese. ${ }^{191}$ The study concluded there was, "no risk of excess death associated with 'overweight' ... that there was little risk of excess death associated with obesity until one reached extremely high weight levels, and that there was a high risk of premature death associated with weight levels just a few pounds below the government's 'recommended' ideal weight." ${ }^{192}$ However, by fighting a war on fat legislators are able to capitalize on the disproportionality of anxiety that exists and justify the implementation bills such as the extra taxation of the sale and rental of DVD's, video games, computer games. ${ }^{193}$

\footnotetext{
${ }^{189}$ B. Wright, "Surgeon general to cops: put down the donuts" http://www.cnn.com/2003/HEALTH/02/28/obesity.police, March 2 2003, Accessed April 22009. ${ }^{190}$ Ibid

${ }^{191}$ K.M. Flegal et al. "Excess Deaths Associated with Underweight, Overweight and Obesity" (2005) 293 $J A M A$ at 1861 .

${ }^{192}$ Campos at 43.

${ }^{193}$ J. Rivera, "Pediatricians' Child Obesity Policy Statement Mirrors Ortiz Bill. National Group Calls for More Community Programs" http://assembly.state.ny.us/comm/Food/20030805/

August 5, 2003, Accessed March 122009.
} 
The final principle component of a moral panic is volatility. ${ }^{194}$ Due to their capricious nature moral panics explode with such ferocity that they cannot be sustained for very long periods; often disappearing just as quickly as they erupted. While the current moral panic involving obesity has not yet subsided, it is comparable with past moral panics that have since vanished, such as America's drug panic in the 1980 's. ${ }^{195}$ Nonetheless, due to the widespread global consensus of the existence of an obesity driven moral panic it is unlikely that this panic will disappear without traces of social control mechanisms such as remnants of legislation, and action groups. ${ }^{196}$

At the forefront of Cohen's analysis of moral panics is the media. Cohen claims that moral panics are born out of the media's exaggeration and over reporting of events. ${ }^{197}$ Due to the previous existence of a morally problematic relationship with the subject of human corpulence, rather than create a new threat what is occurring is simply the manipulation and amplification of existing North American insecurities.

Rather than attempt to apply Cohen's media centric approach to clarify the origins of the current moral panic, a more interconnected approach must be adopted which accounts for the secondary role of the press. This can be partially found in what Goode and Ben-Yehuda refer to as the elite engineered model. The elite engineered model is derived from cultural theorist Stuart Hall's take on the orchestration of a moral panic as a means of garnering social control. ${ }^{198}$ Hall argues in his 1978 book Policing the Crisis:

\footnotetext{
${ }^{194}$ Cohen at 9.

${ }^{195}$ Goode and Ben-Yehuda at 206.

${ }^{196}$ Ibid. at 39.

Action groups can be defined as an often temporary social group created for the purpose of inciting collective change.

${ }^{197}$ Cohen at 17.

${ }^{198}$ S. Hall, Policing the Crisis: Mugging, the State and Law and Order (New York: Palgrave Macmillian, 1978) at 29.
} 
Mugging, the State, and Law and Order ${ }^{199}$ that an increase in fear over street crime unaccompanied by any escalation in street crime qualifies as a moral panic. ${ }^{200} \mathrm{He}$ theorizes that a moral panic occurs when "the official reaction to a person, groups of persons or series of events is out of all proportion to the actual threat offered." ${ }^{201}$ For Hall the moral panic is all about the execution of hegemony as a means from which to control others. It is when crime statistics are over exaggerated and manipulated to create apprehension that social control techniques are easily administered. Hall also argues that a moral panic has little to do with morality, but is simply "a means by which the powerful protect their interests, primarily their economic interests." 202

\section{Who Started this Fat Panic?}

While the elite engineered theory accounts for the influential interests in creating a moral panic, it fails to take into account the North American populations' historically enduring anxiety of human fat. It is through the unlikely fusing of the elite engineered with the grass roots model, that the two formerly opposing models are able to link the relationship between the general publics' first hand experiences with obesity with the interests of the elite; resulting in a form of socially permissible regulation.

The grass roots model of explaining the locus of moral panics, argues that panics originate from the concerns held by the general public. ${ }^{203}$ Arnold Hunt summarizes the grass roots model as follows: "According to this theory, 'politicians and the media cannot fabricate concern where none existed initially,' and moral panics must therefore be founded on genuine public concern, reflected or magnified by the media, perhaps, but

\footnotetext{
${ }^{199}$ Ibid.

${ }^{200}$ Goode and Ben-Yehuda at 135.

${ }^{201}$ Hall at 16.

${ }^{202}$ Goode and Ben-Yehuda at 138.

${ }^{203}$ Ibid. at 127.
} 
arising more or less spontaneously. This is a 'bottom up' rather than 'top down' theory of a moral panic."204 At the centre of the grass roots model is the attitude that people's perceptions are not heavily shaped by the media but are based predominately upon personal experiences found on their own social setting. ${ }^{205}$

By capitalizing on the rise of an existing moral panic, elite organizations such as the Canadian and American governments are able to utilize the public concern surrounding obesity to further their agenda of saving funds by means of a widespread physical downsize. By engaging the media through official announcements denouncing obesity that government ideals become transmitted onto the public, thus actively sustaining a panicked state. In a study which examined the relationship between the obesity driven moral panic and the political elite it is hypothesized that "there would be more reporting on obesity in the year following an official pronouncement about the importance of obesity as a health issue" ${ }^{206}$ However, a timeline of governmental public proclamations emphasizing obesity as a matter of public health shows that while there is a correlation between government announcements and a heightened media concern over the perils being overweight; the statistics gathered failed to connect the current moral panic to elite engineering. ${ }^{207}$

The moral entrepreneurs promoting the current obesity driven moral panic are the American and Canadian governments. In creating a moral panic around obesity North American governments are gaining support for human governance through their

\footnotetext{
204 Arnold Hunt "Moral Panic and Moral Language in the Media"(1997) Vol. 48, Issue 4. The British Journal of Sociology at 636. ${ }^{205}$ Ibid. at 636.

${ }^{206}$ A. Saguy and R. Almeling. "Fat Panic! The "Obesity Epidemic as Moral Panic" Paper presented at the annual meeting of the American Sociological Association, Marriott Hotel, Loews Philadelphia Hotel, Philadelphia, PA, Aug 12, 2005 Accessed March 232009. http://www.allacademic.com/meta/p22928 index.html at 8 . ${ }^{207}$ Ibid.
} 
promotion of a non-obese bodily norm. While the media are central to the endorsement of moral panics their relationship differs from the instigating role of the government. The position played by the media in the moral panic concerning obesity is an exemplification of Cohen's concept of deviancy amplification. By hyping obesity to appear more serious than it actually is, the media is able to garner mass amounts of public anxiety from which to support and prolong the government supported moral panic.

The parallel between the increases in media fervour brought about by a government statement provides a link between that the government's utilization of the media and the prolonging of the moral panic on obesity. It is by maintaining a high level of concern throughout the populace that citizens become increasingly dependent on their government for protection, thus validating the government's often unnecessary presence as essential to societal welfare. In utilizing a moral panic to promote the notion that becoming or remaining fat can be equated to a national security threat, government bodies are sustaining fear in order to create smaller bodies from which to produce smaller expenditures on health while extending the reach of available governing methods. ${ }^{208}$

By proving that "governmental bodies began to make public proclamations about obesity from 2001 on, when media reporting on obesity was already at its highest level" 209 it is clear that the obese moral panic was not entirely born out of elite interests. In relating back to Peter Stern's grass roots argument presented in chapter one which attributes the North American publics' fear of obesity to historically moralized reasons, ${ }^{210}$ the rationale for conjoining the elite model with the grass roots model becomes verified;

\footnotetext{
${ }^{208}$ B. Wright, "Surgeon general to cops: put down the donuts" http://www.cnn.com/2003/HEALTH/02/28/obesity.police, March 2 2003, Accessed April 22009. ${ }^{209}$ Saguy and Almeling at 8.

${ }^{210}$ Ibid.
} 
the moral panic pertaining to obesity was born out of a revival of long-standing North American anxiety. As the obese became a more prominent demographic, historically present feelings of immorality resurged into a panic fuelled by elite sources such as American and Canadian governments. Moreover, these same governments adeptly employed the mass media as a tool to disseminate information from which to sustain the moral panic; thus securing the interests of the elite.

\section{Expanding the Epidemic}

The current buzzword surrounding obesity is epidemic ${ }^{211}$. By extending a moral panic governments are able to transform an average weight gain of nine pounds over fifteen years ${ }^{212}$ into a sweeping pandemic of mass proportions. In creating a false epidemic North American governments become enabled by their population to fulfill the 'something must be done' reaction with that of regulation. Furthermore, the rapidly spreading notion of obesity as a disease has resulted in the impression that those who are not obese may become obese unless regulatory precautions are taken. This misleading sense of danger effectively expands the scope of potential regulatory targets beyond the problematic demographic to virtually everyone. In sustaining the mindset that North American citizens are either the problem, or at risk for becoming a problem, governments are able to take a widespread approach to governance.

What makes the classification of obesity of great consequence to personal regulation is that the criteria of what is classified as obese, is defined by government sanctioned public health authorities. The North American standard measure for obesity is

\footnotetext{
${ }^{211}$ The perceived rapid and uncontrolled spread of obesity occuring throughout North America.

${ }^{212}$ Campos at 9.
} 
the body mass index ${ }^{213}$ which divides a person's weight by their height. Currently obesity is defined by public health authorities as a BMI of thirty while a person with a total of twenty five is classified as being overweight.

Because the measurement of body mass index follows a bell curve, with obesity situated within the centre of the curve, an average national weight gain of even a few pounds will thrust millions of individuals who had BMIs under twenty five and thirty into the classification of obesity. ${ }^{214}$ The American governments' ability to utilize the body mass index scale as a means of expanding the definition of obesity is embodied by the federal government's 1998 decision to decrease the definition of overweight from a BMI of twenty eight to that of twenty five $\mathrm{e}^{215}$; which resulted in the creation of thirty one million overweight American's overnight. ${ }^{216}$ As obesity is a construct of fat's medicalization, the United State's Federal government's use of statistics is a means from which state control is broadened to include more individuals under the classification of obese. Furthermore, one of the faults of the BMI is that by its nature it encompasses those who are muscular and short as obese; some prominent examples of this are actors Tom Cruise and Sylvester Stallone. ${ }^{217}$ The result of utilizing a government controlled standard of measuring obesity is that the definition of obese becomes very inclusive; therefore adding to the false impression of an epidemic.

Whereas the problematization of obesity legalized the fat of North American citizens, its target was limited at those who were already obese. It is by means of a moral panic that the apprehension generated concerning the effects of obesity onto society

\footnotetext{
${ }^{213}$ Hereafter referred to as BMI

${ }^{214}$ Campos at 10.

${ }^{215}$ Ibid.

${ }^{216} \mathrm{Ibid}$.

${ }^{217}$ Ibid. at 81 .
} 
expanded governance to include not just the obese, but those at risk for becoming obese. Furthermore, it is through the preservation of a moral panic that the public concern surrounding obesity remains elevated, and as long as people have a heightened concern about obesity then this expanded regulatory format is available. However, what moral panic does not address is a strict governing method from which to implement regulatory tactics. Regardless of having access to a receptive and governable audience, a gap still exists between the ability to govern and the process of actually implementing a regimen of governance targeted at obesity.

While the problematization of obesity created a target for governance and a moral panic increased the number of viable regulatory targets, neither suggests a practical method from which the governance of obesity can be implemented. Therefore, it is within the focus of my next chapter that I will utilize the Foucaultian concept of governmentality to connect the expanded governing potential made accessible through a moral panic, with the means of implementing obesity targeted regulation. 


\section{Chapter IV : Governmentality \& Obesity}

By taking a three part approach to make sense of the current governance of obesity, governmentality represents the final segment. While problematization and moral panic theory generates a means by which morality is able to motivate widespread tactics of human governance, what these theories cannot account for is a regulatory strategy from which government authority is able to restructure human bodies without appearing oppressive. The Canadian and American governments' current regulatory scheme to decrease obesity without public resistance can be clarified by reference to Foucault's theories of governmentality and biopower. By applying Foucaultian theories of governance to obesity a strong parallel can be developed between Foucault's theorizations and the current governing approach of North American governments. In utilizing Foucault to make sense of the contemporary governing styles of the United States and Canadian governments, I will first examine governmentality and its associative concept of biopower, followed by an application to the wide array of governing tactics put forth by North American governments with which to physically downsize their populations in order to minimize fiscal expenditures.

\section{Foucault's Governmentality}

Often described by Foucault as the art of government, ${ }^{218}$ governmentality can best be defined as the practices through which citizens are governed in order to adequately

\footnotetext{
${ }^{218}$ M. Foucault, Naissance de la biopolitique: cours au College de France (1978-1979) (Paris: Gillimard \& Seuil:2001).
} 
fulfill government policies. ${ }^{219}$ In order to fully understand the concept of governmentality, one must have a grasp of Foucault's definition of government. Rather than comply with the modern understanding of government as a predominantly political term, ${ }^{220}$ Foucault places the term government within the broader meaning of influencing day to day living, from which to shape the 'conduct of conduct'. ${ }^{221}$ Foucault examines the idea of government as something which has in the past extended beyond state administration into guidance for household living, the family, and spirituality. ${ }^{222}$

For Foucault, government power is about guidance which manifests in its ability to influence human conduct, as "from the perspective of those who seek to govern, human conduct is conceived as something that can be regulated, controlled, shaped, and turned into specific ends." 223 It is by means of structuring the realm of possible actions that government can shape human conduct. ${ }^{224}$ This approach to government directly connects issues of governance to issues of bodily space and personhood.

As morality plays a central role in the issue of obesity, it is also present in Foucault's characterization of government. In assuming that at the root of morality is personal accountability and that human beings are self-regulated based on moral behaviour, then the practice of government influenced self governance is inherently moral. ${ }^{225}$ In order for Foucault's theories about self governance to function, the relationship between the governors and the governed must be based upon moral

${ }^{219}$ T. Lemke, "The birth of bio-politics: Michael Foucault's lectures at the College de France on neoliberal governmentality" (2001) v.30, i.2, Economy and Society at 2.

${ }^{220}$ T. Lemke, "Foucault, Governmentality and Critique" Conference Presentation at 2.

${ }^{221}$ M. Dean, Governmentality: Power and Rule in Modern Society (London: Sage Publications, 1999) at 11.

${ }^{222}$ T. Lemke, "Foucault, Governmentality and Critique" Conference Presentation at 2.

${ }^{223}$ Dean at 11

${ }^{224} \mathrm{Ibid}$. at 14.

${ }^{225}$ Ibid. at 11. 
rationality; the ability to govern accountably through consistent methods. ${ }^{226}$ Subsequently, without a basis in morality self governance would be inconceivable.

Therefore, as put forth by Mitchell Dean, "the notion of government extends to cover the way in which an individual questions his or her own conduct... so that she or he may be better able to govern it." ${ }^{, 227}$ By this standard, government includes not only how authority is implemented upon others, or how populations are governed, but how one governs the self. $^{228}$ Foucault's conceptualization of government provides a direct link between government and self government; or the conduct of conduct. ${ }^{229}$

The governance of the self or governmentality can be broken into four aspects. The first feature of governmentality derives concern with how the target in question is governed. ${ }^{230}$ The second involves the target which is acted upon; this can also be referred to as the governed. ${ }^{231}$ The third aspect is concerned with the reasons why we are governed or govern, and finally who we are when we are subject to governance. ${ }^{232}$

As governmentality extends government into the most intimate reaches of human life it is not surprising that governmentality is closely tied with economics. ${ }^{233}$ By governing through the economy happiness and prosperity of the population are ensured. $^{234}$

The tie between government, the self, and the economy is central to my analysis of the governance of obesity. The high cost that obesity places upon the health care system

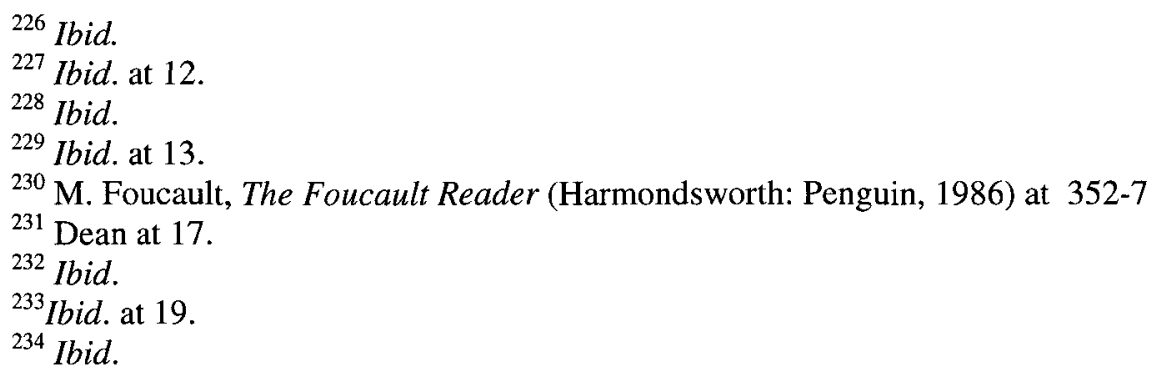


and the overall economy provides governments with an impetus to regulate the human body. As North American governments are allotting society's resources in a manner with which to achieve their own opportunistic goal of saving money by means of reducing obesity, the governments' method of control can be viewed as economic regulation. Furthermore, it is by focusing on governmentality and biopower that a connection between physical bodies and governance is further established.

Biopower represents the government's ability to regulate the behaviour of an entire population through a wide array of control techniques. ${ }^{235}$ Born out of the power over life, biopower concerns the discipline of the body and the regulation of the population. ${ }^{236}$ Unlike the broad focus of governmentality, biopower concentrates on the politics of the human body, such as the mechanics of life, health and longevity. ${ }^{237}$ Furthermore, Foucault credits biopower with playing a vital role in capitalism, in that it inserted physical human bodies into the mechanisms of production and thus increased economic capital. $^{238}$ It is by having power over life that governments are able channel human decision making towards results which are the most economically beneficial for the state.

What makes Foucaultian concepts of governance a successful means of shaping human behaviour is that it accomplishes its goals without seeming to threaten human autonomy. While human beings believe they are acting as independent and autonomous individuals, they are actually complying to fulfill the political objectives of those governing. ${ }^{239}$ Furthermore, by regulating through self-governance, North American

\footnotetext{
${ }^{235}$ M. Foucault. The History of Sexuality an Introduction Volume 1 (New York: Random House, 1978) at 140.

${ }^{236} \mathrm{Ibid}$. at 143.

${ }^{237}$ Ibid. at 139.

${ }^{238}$ Ibid. at 141 .

${ }^{239}$ This is consistent with Foucault's view of domination.
} 
governments become reliant on the indirect techniques of controlling populations without being responsible for them. This non-responsibility is accomplished through the process of responsibilization. Responsibilization occurs from public education concerning various social risks such as death, illness, and poverty. ${ }^{240}$ By educating the public about societal perils what was once the responsibility of the state becomes transformed into individual responsibility and a problem of self-care. ${ }^{241}$ For example, rather than simply address the needs of obese Canadians through the publicly funded healthcare system, the Canadian government is putting the onus on its citizens to avoid using the system by maintaining a government mandated BMI.

\section{$\underline{\text { Responsibilization }}$}

As the subject of health is not immune to responsibilization, what occurs is a combination of responsibilization and health, referred to as healthism. ${ }^{242}$ The rationale behind the responsibilization of health is as follows: as it is in the publics' best interest to want to extend their own lives through healthy living, they do so based on their own sense of personal fulfillment, regardless of political objective. ${ }^{243}$ However, the relationship between the responsibilization of health and the politics of governance is more complicated than simply the manifestation of a desire to exist, as Nikolas Rose states:

[the responsibilization of health] links public objectives for the good health and good order of the social body with the desire of individuals for personal health and wellbeing. A private ethic of good health and morality can

\footnotetext{
${ }^{240}$ T. Lemke, "The birth of bio-politics: Michael Foucault's lectures at the College de France on neo-liberal governmentality" (2001) v.30, i.2, Economy and Society at 12. 241 Ibid.

${ }^{242}$ N. Rose. Powers of Freedom: reframing political thought. (Cambridge: Cambridge University Press 1999) at 86.

${ }^{243}$ Ibid. at 87.
} 
thus be articulated on to a public ethic of social order ...yet without destroying the autonomy of the family indeed promising to enhance it. ${ }^{244}$

It is by acting in accordance with the principles of responsibilization that individual personal goals become integrated with political goals, and thus become governable. Therefore, in placing the responsibility of obesity onto individuals and causing them to react in ways that carry out the government's agenda, such as going to the gym, they can then be transformed into governed bodies. In applying biopower to the responsibilization of health, biopower's ability to both extend the government's capacity to regulate, as well as operate under the guise of public welfare becomes unmistakably obvious to those seeking a method of explanation, while remaining hidden to the public.

With regards to obesity, modern governments are utilizing biopower to focus on the manipulation of an entire population of human bodies through numerous and diverse methods all aimed at self regulation. ${ }^{245}$ Furthermore it is through the responsibilization of obesity that North American governments are able to situate the onus of mitigating obesity onto the general population. It is because biopower operates through such diverse forms of control techniques, ${ }^{246}$ that the government can implement intrusive regulations which challenge human autonomy and ultimately remain unnoticed. It is this invisible method of regulating human autonomy through discourses on obesity among others in order to execute government strategies that makes biopower such an effective model of human governance.

\footnotetext{
244 Ibid. at 74.

${ }^{245}$ Foucault 1978 at 140.

${ }^{246}$ That from blatant anti-obesity legislation such Mississippi Legislatures House Bill 282 which prevents obese individuals from being served in restaurants, to more subtle forms of governance including the fortification of unhealthy foods with vitamins.
} 


\section{Governmentality and the Governance of Obesity}

In order to demonstrate the correlation between the governing approach of North American governments and Foucault's theorizations of governance and biopower, I will explore the diverse forms of regulation all directed altering human conduct to obstruct the growth of obesity. By taking an approach which examines the relationship between obesity and North American governments regulating tactics, the first two aspects of Foucault's criteria for governance concerning who the target is and how the target is governed becomes established.

As demonstrated by means of moral panic, individuals are either obese, or at risk of becoming obese and therefore the governing target is the entire North American population. Without the existence of a moral panic, the targets of regulation would be limited to the obese and the rest of society would not pose the same threat and therefore require regulation. However, as Foucault's definition of governance encompasses action that influences conduct, its expansive nature accounts for the wide array of governing targets made available through moral panic. Furthermore, because Foucault's concept of governance is so wide ranging, the relationship between the governed and governor is often complex. Rather than limit the relationship of governance as extending from the governed to the governor, ${ }^{247}$ Foucault's concept of governmentality creates governors out of the governed. ${ }^{248}$ In regards to obesity this complex approach to governance subjects the entire North American population to the regulatory powers of American and Canadian governments which is then strengthened by the ability of the governed to then govern others. Moreover, while the obesity driven moral panic substantially increased

\footnotetext{
${ }^{247}$ such as the government to its citizens

${ }^{248}$ A previous example being the relationship between parents who are governed by the government's antiobesity campaigns and intern govern their children to avoid becoming obese.
} 
the available regulatory targets, the cohesive web of governance presented through governmentality ensures that regardless of how many individuals become governed, the effectiveness of the intended regulatory strategy will not be compromised.

As the distribution of governing techniques being implemented to hinder obesity are so wide-ranging in order to provide a proper analyses of obesity governance, two very broad categories must be constructed. The first category is formal legislation, while the second category is health based governing measures aimed primarily at children. By utilizing these categories the complex regulatory strategy surrounding obesity may be streamlined into a systematic format from which a coherent analysis of obesity governance can take place. While problematization gave legitimacy to the use of law in regards to the previously private issue of obesity, and moral panic expanded the available target of governance, governmentality provides the regulatory means through which obesity governance is achieved. Furthermore, it is through governmentality that the social stigmas that motivated the problematization of obesity are reflected within the states governance of obesity.

\section{$\underline{\text { Policy and Legislation }}$}

The first regulatory tactic of governing obesity can be found within the spectrum of policy and legislation. It is by means of crafting legislation that government authorities can have a direct impact upon the body weight of their citizens. Furthermore, by creating legislation that targets multiple aspect of one's personal life, Foucault's notion of the expansive government taking place within multiple facets of human life becomes 
apparent. ${ }^{249}$ As previously noted, the amount of obesity bills presented to the American congress has seen an unprecedented increase since the 1980 's. ${ }^{250}$ The expansive set of bills found both in America and Canada have a range of targets equally as extensive. ${ }^{251}$ While some of the legislation put forth to hinder obesity, such as Mississippi's proposed House Bill $282^{252}$ which attempted to ban the serving of obese individuals at restaurants, may seem forthright such blatant intrusiveness is rarely the case. The Foucaultian style of obesity regulation as implemented by North American governments operates through extremely varied measures and can be demonstrated by a simple overview of the anti-obesity legislation both proposed and enacted within the United States and Canada.

The first set of laws aimed at reshaping the North American population are the so called 'fat taxes', the attachment of extra tax on unhealthy food thought to cause obesity. ${ }^{253}$ These laws act as both a deterrent and a source of extra funds from which to alleviate the cost that obesity places upon the health care system and losses in workplace productivity. ${ }^{254}$ The latest proposed obesity tax was in Albany New York where the governor petitioned to add an additional $15 \%$ tax on non-diet soft drinks. ${ }^{255}$ Currently anti-obesity taxes have been supported by various public health authorities including the

\footnotetext{
${ }^{249}$ Dean at 13 .

${ }^{250}$ P. Campos, "The The Legalization of Fat: Law, Science, and the Construction of a Moral Panic" (March 3, 2006). Bepress Legal Series. Working Paper at 20.

${ }^{251}$ However, while American laws tend to target the individual outright, Canadian laws take a much different approach in regulate against obesity in a more detached fashion (such as tax cuts for fitness participation) this differing approach results in an extensive variance in available legislation.

${ }^{252}$ Mississippi Legislature 2008 Regular Session House Bill 282.

${ }^{253}$ Campos at 21.

${ }^{254} \mathrm{~L}$. Gostin, “Law as a tool to facilitate healthier lifestyles and prevent obesity“(2007) JAMA. Jan 3, 297 at 87.

${ }^{255}$ G. Blain, “Governor Paterson proposes 'Obesity Tax,' a tax on non-diet sodas“ Daily News Albany Bureau. Sunday December $14^{\text {th }} 2008,11: 37 \mathrm{pm}$
} 
World Health Organization. ${ }^{256}$ The anti-obesity taxes aim to decrease human body weight by allowing obese individuals to remain autonomous and independent in their decision making authority. However in increasing the cost of high caloric food both obese and non-obese, individuals become steered towards the lower priced healthier alternative. The creation of an economic deterrent to stop individuals from purchasing unhealthy food is a much less obvious technique of mitigating obesity than simply legislating the prohibition of the obese from purchasing high caloric snack foods. Furthermore, laws such as fat taxes are not specific to the governance of obese bodies but are effectively subject to the entire snack buying demographic; culminating in a very high percentage of non-obese society.

A spectrum of ways with which the Canadian federal government is able to govern obese bodies is through legislation which provides monetary incentives for living a life compliant with North America's anti-obesity regimen. Fitness initiatives such as the Children's Fitness Tax Credit ${ }^{257}$ which allows parents to gain additional tax benefits from enrolling their children in various sporting activities, and the Winter Active and Summer Active $^{258}$ campaigns, are also sources of government regulation which extends to the inner most personal reaches of human society. By means of regulations such as these, governments are effectively able to regulate the conduct of conduct in order to minimize the financial cost caused by human bodies containing excess fat. Furthermore obesity

\footnotetext{
${ }^{256}$ Gostin at 89 .

${ }^{257}$ Government of Canada, Childhood Obesity and the Role of the Government of Canada. 2007. Available online http://www.phac-aspc.gc.ca/ch-se/obesity/pdf/chobesity_e.pdf at 2.

${ }^{258}$ Ibid.
} 
governance is occurring even in the promotion of behavioural guides such as Canada's Physical Activity Guide, ${ }^{259}$ and the Canadian educational initiative of ParticpACTION. ${ }^{260}$ Through government sanctioned initiatives such as ParticipACTION and the Physical Activity Guide, the Canadian government is able to create a setting of responsibilization whereas the onus is on the citizen to become active in order to comply and promote their own bodily reconfiguration in order to do their part in helping to save the Canadian government's money by remaining healthy.

While the increasing of bike paths does not seem like a form of human governance, it is. The most unobvious way in which North American governments are regulating obesity is through the restructuring of infrastructure and built environment. ${ }^{261}$ As a major contributor to obesity is said to be the suburb, ${ }^{262}$ government attention to obesity is heavily focused on reconfiguring the structure of North American communities. It is by altering city infrastructures that governments are seeking to "limit the number of fast food restaurants, build recreational parks and bike paths, expand mass transportation, and provide incentives to stores that sell nutritious and affordable foods. ${ }^{.263}$ Furthermore, in urban settings government's are attempting to implement more green areas from which to promote physical activity. ${ }^{264}$

In compliance with the initiative to reduce obesity by means of altering infrastructure, the Canadian government has introduced a $\$ 3.3$ billion plan entitled Building Canada from which to alter Canadian city structure to create slimmer citizens

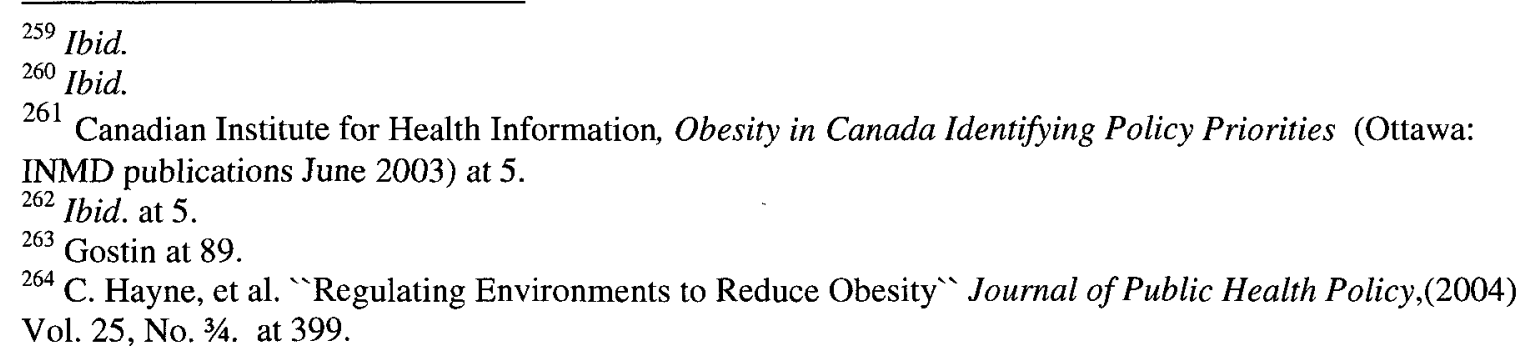


through the creating of infrastructures which promote walking. ${ }^{265}$ In the United States such anti-obesity infrastructure changes are endorsed by The National Association of County and City Public Health Officials as well as Congress. ${ }^{266}$ As the altering of physical landscape is not usually considered a form of bodily governance, it represents the most unapparent means from which obesity regulation is achieved by North American governments.

Another form in which obesity governance is being implemented is by means of government sanctioned food prohibitions. ${ }^{267}$ It is by controlling the content of North American's food sources that governments are able specifically to control what ingredients their populations are able to consume. As a result of removing high caloric ingredients from available foods, American and Canadian governments are able to further govern the size of their citizens by controlling their diets. However, rather than directly criminalize the consumption of unhealthy forms of fat the Canadian government is currently taking steps to ban the inclusion of trans-fats, the unsaturated forms of fat which are known to increase rates of heart disease and obesity ${ }^{268}$ from being included within food Canadian products. Health Canada's calls for the monitoring and decline of trans-fats in Canadian food products, ${ }^{269}$ have been mirrored by action undertaken by the Canadian government. In 2007 the Canadian government vowed to regulate trans-fats to a content level of under five percent by 2009. Included in Canada's proposed trans-fat bans is the opportunity for the food industry to self regulate trans-fats to the desired five

\footnotetext{
265 Canadian Institute for Health Regulation at 2.

${ }^{266}$ Hayne, at 399.

${ }^{267}$ Gostin, at 88 .

${ }^{268}$ Food and nutrition board, institute of medicine of the national academies, 'Dietary Reference Intakes for Energy, Carbohydrate, Fiber, Fat, Fatty Acids, Cholesterol, Protein, and Amino Acids (Macronutrients). " (Washington: National Academies Press, 2009) at 504 .

${ }^{269}$ Health Canada, 'Food and Nutrition: Trans fat" (2009) http://www.hc-sc.gc.ca/fn-an/nutrition/grastrans-fats/index-eng.php.
} 
percent level. ${ }^{270}$ Furthermore, in March of 2009 the provincial government of British Columbia announced that it would restrict trans-fats in all food prepared and served by restaurants in the province. ${ }^{271}$ However, rather than view Canada`s ban on trans-fats as giving the food industry unfettered self regulation, it is simply the Canadian government allowing for flexibility within their anti trans-fat requirements with which the food industry must comply.

Through the disclosure process of labelling foods America's Food and Drug administration are seeking to reduce obesity through the mandate of providing the consumer with information concerning the contents of food, both in grocery stores and in restaurants. ${ }^{272}$ States such as New York ${ }^{273}$ and California ${ }^{274}$ have already passed laws which require restaurants to display the calorie count of all food items on the menu. By displaying the caloric content of food, governments are able to regulate everyone, both the obese and the potentially obese by altering their choices of action by means of simply disclosing information.

Another way in which the Canadian government is seeking to utilize regulation to alter the ingredients in food available to Canadian consumers is through the fortification of unhealthy foods with vitamins such as calcium and iron. ${ }^{275}$ It is thought that by adding vitamins to unhealthy foods the affects of a nutrient deficient diet will be mitigated thus

\footnotetext{
${ }^{270}$ Health Canada. "Canada's New Government Calls on Industry to Adopt Limits for Trans Fat". June 2007. http://www.hc-sc.gc.ca/ahc-asc/media/nr-cp/2007/2007 74 e.html.

${ }^{271}$ A. McKinnon British Columbia Ministry of Healthy Living and Sport "Province restricts trans fat in B.C.'. Press release. (March 7, 2009). http://www2.news.gov.bc.ca/news releases 20052009/2009HLS0013-000315.htm. ${ }^{272}$ Food, Drug and Cosmetic Act, 21 U.S.C. 321(n), 343(a) (1994).

${ }^{273}$ New York State Restaurant Association (NYSRA) v. New York Department of Health, http://www.citizen.org/litigation/forms/cases/CaseDetails.cfm?cID $=420$

${ }^{274}$ California House Bill SB 1420 2007-2008 Session.

${ }^{275}$ Health Canada, “Questions and Answers - Food Fortification Proposed Policy“'June 2007. http://www.hc-sc.gc.ca/fn-an/nutrition/vitamin/faqs-eng.php
} 
leaving Canadians who disregard health initiatives as remaining within the reach of Canadian obesity governance. ${ }^{276}$

The major focus of North America's legislative governance of obesity is children. It is by aiming regulation at the bodies of children that governments are able to take a more paternalistic approach at stopping obesity. Furthermore, unlike other methods of obesity legislation, obesity governance aimed at children stems not from the legislature but from health and public health sources which aim to protect children's health through the management of food intake and physical exercise.

While the motives of healthism are said to differ from bio-power based upon the self interest of keeping oneself in good health, ${ }^{277}$ the practice of remaining in good health is compliant with the governments' goals of veiled obesity governance. Therefore, if an individual's goal of remaining or becoming healthy is derived from the need to comply with the societal influence stemming from morality which condemns obesity as problematic, then the line between healthism and obesity governance becomes indecipherable.

Furthermore, when governing children governments are able to increase the number of regulatory mechanisms available in the name of prevention, than would be permitted when governing adults. By aiming blatant anti-obesity legislation at children through the conduit of healthy living, parents become responsible for the weight of the children. This responsibilization of adults makes them subject to North American techniques of antiobesity governance, which on their face appear to apply only to children. By influencing

\footnotetext{
${ }^{276}$ This form of food fortification can currently be found within a multitude of products within Canadian grocery stores such as Pogos.

${ }^{277}$ N. Rose, Powers of Freedom: reframing political thought. (Cambridge: Cambridge University Press 1999) at 74.
} 
their children to alter their behaviour to prevent obesity those in charge of youth become both the governed and governors.

It is through the school atmosphere that obesity regulation is most easily implemented. By altering daily variables that influence a child's eating and physical activity levels, children become subject to governance aimed at reducing the fat content present within their bodies. Therefore, the majority of health based legislation present within schools is aimed at diet and exercise. ${ }^{278}$

An example of a popular legislative strategy being implemented within schools across the United States and Canada is the banning of unhealthy food and drink, most often dispensed by means of corporate sponsored vending machines. The Junk Food and Soda Free Schools Act ${ }^{279}$ in New York city is an example of one of many initiatives taken by state governments to alter the diets of the youth population by removing unhealthy foods from school premises.

While physical education classes are available in almost every elementary and high school across North America, in some American states mandatory student enrolment in such classes is mandated by law. ${ }^{280}$ Furthermore, the Canadian federal government has published reports which express a similar desire for the regulation of mandatory physical education classes in both elementary and high schools. ${ }^{281}$

Additionally, some American states such as Arkansas have begun annually

\footnotetext{
${ }^{278}$ International Obesity Task Force, “'Global strategies to prevent Childhood obesity: Forging a societal plan that works" A discussions paper prepared for the Global Prevention Alliance McGill Integrative Health Challenge October 26-27 2006.

${ }^{279}$ Junk Food and Soda Free Schools Act. City of New York City Council. Int. No 306.

${ }^{280}$ Required physical activity in schools Acts 2004, Louisiana Legislature.,No. 734, §1, eff. July 6, 2004.

${ }^{281}$ Canadian Institute for Health Information at 8.
} 
monitoring elementary school children's body mass index. ${ }^{282}$ The results of each child's body mass index classification is utilized both for medical statistics and is reported back to each child's respective guardian, and comes complete with suggestions from which parents are able remedy the situation through increased physical activity and better nutrition. $^{283}$

As statistics are being used to shape the actions of parents and encourage weight loss in children, statistics are therefore active forms of Foucaultian governance. Rather than collect statistical data for informational purposes, the gathering of American school children's body mass index scores are being used to influence human conduct to fulfill the government's goal of creating a physically smaller population. Furthermore, the use of statistics concerning the promotion of child health effectively responsibilizes parents as it places the moral impetus upon parental guardians to comply with the aim of the statistics; keeping children within the government's prescribed weight category.

It is important to note that the tactics taken by governing agents directed at North American youth are more apparent than those which are targeted at adults. The reasoning behind this obtrusive form of youth governance is that paternalism becomes increasingly justified by society when it is for the good of the children. Because of this more direct steps are taken by government authorities to alter the lives of children to acquire the desired results of thinness.

Unbeknownst to the many adults who agree to the stiffer forms of governance used to prevent child obesity, through responsibilization the same measures being used to

\footnotetext{
${ }^{282}$ J. Raczynski, “Arkansas Act 1220 of 2003 to Reduce Childhood Obesity: Its Implementation and Impact on Child and Adolescent Body Mass Index" (2009) Journal of Public Health Policy, Volume 30, Supplement 1, 2009 at 124- 140

${ }^{283}$ Arkansas' School BMI Assessment, National Association of State Boards of Education. Vol. 12, No. 1 January 2007. http://nasbe.org/index.php/shs/80-he-project-news/132-arkansas-school-bmi-assessment
} 
govern children are then applied to them. It is because parents are in charge of the domestic atmosphere that parents influence a child's "food selection, meal structure, and home eating patterns: their modeling of healthful eating practices, their levels of physical activity; and their modeling of sedentary habits including television viewing are all influential in their children's development of lifelong habits that contribute to normal weight or to overweight and obesity." 284 While the parents are themselves being governed by adhering to the North American government's goal of reducing obesity, they are also actively governing through altering the actions of their children; the control implemented by parents on their children can be viewed as an assertion of biopower. Foucault's concept of governing the politics of the human body in order to promote physical health and longevity is accomplished through parental governance which focuses on creating an atmosphere that governs on behalf of the health of children. Furthermore, the approach taken by parents does not focus on a single contributing factor to obesity, but takes a broad and complex approach which concentrates on a multitude of factors, such as physical activity, eating habits and television viewing. ${ }^{285}$

Because of the parents central role in structuring their child's environment government and health initiatives extended their governance onto adults by administering them as role models who must alter their behaviour in order to provide proper guidance and structure to reduce obesity in American and Canadian children.

By responsibilizing adults to govern themselves and their children, governments are able to enact legislation that permeate deep into the family structure and alter behaviour based upon the want for a physically smaller population under the guise of

${ }^{284}$ A. Lindsay, “'The role of parents in preventing child obesity" (Spring 2006) Future of Children vol. 16 No. 1 at 170.

${ }^{285}$ Ibid. 
child based governance. Currently some school based programs being implemented which connect parental actions with their children's weight are Planet Health, ${ }^{286}$ Eat Well and Keep Moving, ${ }^{287}$ and the Special Supplemental Nutrition Program for Women, Infants and Children ${ }^{288}$ the American public health initiative which goes so far as to regulates the in uterine environment to reduce rates of childhood obesity.

As demonstrated by the varied forms of policies and legislative measures being undertaken by American and Canadian governments provide a seemingly indistinct and widespread framework from which to govern the obesity of North American population. While the diverse forms of regulatory tactics being undertaken by governments is the primary cause for the unobvious nature of obesity governance, its unobtrusiveness also must be attributed to Foucault's definition of governance. Rather than define the success of governance as showing complete compliance to the desires of the governing body, Foucault's definition of governance can be satisfied through the subtle means of altering one's conduct. ${ }^{289}$ Given this definition of governance, even in the performance of seemingly mundane tasks individuals still become situated as acting in accordance with government objectives. While the decision to choose diet soft drinks over the higher caloric alternative may seem both insignificant and limited to personal choice, it is a decision with which government agenda is successfully carried out by the often obliviously governed individual. Because Foucault's concept of governance can be executed through even the most minimal forms of human action, combined with the vast

${ }^{286}$ S. Gortmaker, “'Reducing Obesity via school-based interdisciplinary Intervention among youth: Planet Health" (1999) Archives of pediatric and adolescent medicine 153, no 9 at 1- 10.

${ }^{287}$ S. Gortmaker, "Impact of a school-based interdisciplinary intervention on Diet and physical activity among urban Primary school children: Eat well and keep moving." Archives of pediatric and adolescent medicine (1999) 153, no 9. at 975-83

${ }^{288}$ M. Ver Ploeg, "WIC and the Battle Against Childhood Overweight Economic Brief "'(2009) No. (EB13) United States Department of Agriculture, Economic Research Service at 4.

${ }^{289}$ T. Lemke at 5. 
array of regulatory frameworks implemented by the American and Canadian governments, human governance is achieved without infringing the decision making authority of their citizens. Furthermore, as a result of implementing Foucaultian forms of governance those who would otherwise resist government interventions become unknowingly subject.

In a framework through which obese individuals are governed to become thin, governmentality does more than input government objectives into the bodies of North American citizens; it affects the personhood of those being governed. Rather than view the notion of personhood as a strictly legal concept involving the subjection of humans to rules of law and morality, ${ }^{290}$ I will adopt G. Hegel's approach which attributes personhood as a product of society's moral and legal practices. ${ }^{291}$ In Hegel's view of personhood can be understood as a product of social awareness:

It is not a prior concept of personal identity which explains why we are able to participate in these practices; it is rather that because we participate in these practices that we acquire the appropriate identity. Morality and the law have an essentially performative aspect: by participating in them, we are deemed to be a person of that kind. ${ }^{292}$

It is because personhood and identity are a result of societal consciousness produced from "a range of legal institutions, moral frameworks and practices of mutual recognition" 293 that a connection can be established in which governance exerts influence onto the personhood of those governed.

\footnotetext{
290 John Locke, An Essay Concerning Human Understanding (Oxford: Clarendon Press, 1984) II, XXVII.

${ }^{291}$ R. Poole, "On Being a Person" (1996) 74 , Australasian Journal of Philosophy at 48.

${ }^{292}$ Ibid.

${ }^{293} \mathrm{Ibid}$. at 51 .
} 
As the problematization and ultimately regulation of obesity was motivated by the moralization of fat, the governance of the shape human body undoubtedly impacts the personhood of those being governed. Through the governing of obesity and the implementation of multiple forms of regulations all aimed at altering the size of humans to ensure greater financial gain to North American governments, through the better health of individuals such modes of governance result in a population compliant who internalize the goals of the state within their bodies.

By governing the North American population to lessen rates of obesity, body weight is placed at the forefront of identity. As obese individuals already internalize the societal stigmatization of obesity, they view their bodies as problematic to the rest of society. In recognizing their size as a form of physical immorality obese individuals become submissive to outside influences aimed at reducing their physical fat content. Because their identity is marred by negative self perceptions, the obese are susceptible to governing techniques which aim to remedy there perceived immoral state of physical corpulence. Furthermore, governance does not construct a population which stigmatizes fat it simply affirms and capitalizes on society's existing weight insecurities.

As the current moral panic concerning obesity has expanded the available targets for regulation to include not just the obese, but the potentially obese, governance has spawned a regulatory motivated population. It is that through the participation of regulation that the goals of the state become intertwined with the identities of the governed. However, rather than simply agree to regulations put forth by the state, those who are governed still maintain their decision making authority. What occurs through governmentality is that while personal autonomy appears to remains intact, it is 
structured through regulatory mechanisms to produce a singular result which benefits the American and Canadian governments. Whereas individuals believe they are making decisions based upon personal choice, their decisions are often heavily influenced by the anti-obesity regulatory strategy.

The influence of biopower is easily derived from the content of the North American regulatory strategy against obesity. As Foucault's notion of government expands into the family, biopower extends governance onto issues of bodily health such as obesity. By producing bodies that become disciplined into making decisions to both lose weight and influence others to do the same, the goals of biopower are fulfilled. Furthermore, creating an abundance of vastly different forms of regulations stemming from changes to city infrastructure to the removal of school vending machines, direct personal choices become easily influenced without seeming to be infringed upon. Due to the current governing style of North American governments which follows the methods of governmentality and biopower, the perceived autonomy of inherently personal decisions such as those involving corporal and family are directly influenced by American and Canadian political agendas. Through the governance of obesity biopower fulfills its main objective of keeping bodies healthy in order to execute policies of creating and sustaining the productive members of society who add to economic capital rather than require it. 


\section{Conclusion}

As a result of my analysis of the North American governments' methods for the regulation of obesity and its accompanying social acceptance, a different depiction of governance is revealed. Instead of governing individuals through a limited number of law and regulations directly targeted at the problem ${ }^{294}$, obesity is governed within a dense environment of social stigma, anxiety, and regulation. Unlike other traditionally governable targets, obesity is distinctive in a multitude of ways: firstly the problematized component of fat is physically attached to human beings. Secondly excess weight must be regulated in a way that accounts for the autonomy of those with which it is affixed. Furthermore, the regulatory aims of both American and Canadian governments are to reduce the body weight of their population. In order for governance to be effective a deficit between caloric output and intake must occur within millions of people; thus placing the onus of regulatory success onto their citizens.

As a result of utilizing a theoretical framework which includes moral panic, governmentality and its derivative of problematization, the entire process behind human governance is exposed. This distinctive framework specifically situates governance as an after effect of an existing condition that is motivated by the Canadian and American governments' fiscal wants. It is with this approach that the relationship between obesity and governance can be fully clarified; regulation is simply a social construct that was attached to obesity in order to govern the North American population. Furthermore, government interests are reinforced and expanded through the use of widespread anxiety found within a moral panic. Additionally, it is largely because of the precedent of stigma attached to obesity, that the current government initiative is able to regulate the fat

\footnotetext{
${ }^{294}$ Such as an anti-smoking ban
} 
content of the human body.

The governance of obesity is not a simple task; while losing weight is hard enough for most people, convincing millions of people that they should alter their lifestyle in order to reduce their weight is a complicated process. Within the governance of obesity there are two separate parties: the North American government, and the governed public. While the government is promoting the reduction of obesity to save money through financial expenditures stemming from health care costs, the public's reasons for losing weight stems primarily from the self interested desire to increase their health and personal aesthetics.

Even though the regulatory motivations of the government differ from those of the public, rather than remain entirely bifurcated the relationship between both parties is closely intertwined. The implementation of the North American governments' regulatory aims for reducing obesity is almost entirely dependent upon the North American population. Furthermore, as revealed by Stanley Cohen's study of the moral panic, when populations feel that there is a perceived threat stemming from an identifiable group such as the obese, they look to the governments to take action. By playing on the stigmas that are present within society, financially motivated state goals become intertwined with personal impetus to avoid obesity. It is this seemingly unified approach that makes the American and Canadian governance of obesity so effective. While each government is controlling their citizens to save money, the governed population responds by appealing to their respective governments to take action against the supposed epidemic of obesity. However, while both parties are interconnected within the governance of fat, as established through the use of governmentality, regulation is diverse enough that 
government involvement appears reduced.

As a government agenda seeking to diminish obesity cannot be successful without the involvement of the bodies they are trying to govern, the public's participation is essential. Central to the successful regulation of obesity is the government's detachment from governance. While the option exists of legislating obesity more directly, as demonstrated by the failure of bills which are explicit in their attempt to regulate the actions of the individual $^{295}$ a distanced approach to regulation is necessary for public acceptance. Obesity is unique in that for governance to be implemented the targeted population must want to be governed, while actively governing themselves. As demonstrated through my analysis of governmentality, the interchangeable relationship between the governed and the governor results in the perception of a false sense of self governance. Whereas individuals believe they are making independent and autonomous decisions, their actions are often unknowingly influenced by the multitude of regulations aimed at altering human behaviour to decrease their physical size. It is by maintaining this sense of self governance that governments are able to avoid public opposition to their strategy of governing the North American population by means of their fat content.

While other equally expensive physical ailments may exist, due to its obvious appearance and stigmatized nature obesity lends itself easily as a target for state governance. As North Americans are already uneasy about obese people, they are consequently afraid of becoming obese themselves. Therefore, by problematizing obesity and formally including existing stigmas within the regulatory grip of American and Canadian law governments are able to utilize formal regulation to exploit the formerly

\footnotetext{
${ }^{295}$ Mississippi Legislature's Bill 282 which sought to ban the serving of food to obese individuals in restaurants.
} 
non-legal stigmatization of fat. Because fat is widely stigmatized government involvement is viewed as an acceptable measure from which to uphold the moral values of North American society, which included a minimal surplus of excess body fat. Furthermore, the ability of obese individuals to internalize social stigma and adopt a negative self perception may further increase the ease at which obesity is able to become a governable commodity. ${ }^{296}$

As the biological phenomenon of human fat predates formal methods of governance, obesity has existed as a staple in society without regulatory interference. Given that obesity was around prior to its legal problematization, the question of alternatives to regulation should be explored. While current governments are utilizing various methods of regulations to influence their citizens to reduce their size, there are other, possibly more effective means of governing obesity the exist.

The first alternative to formal regulation may be found in the sole use of nonformal governing techniques. Rather than utilize formal legal methods to govern obesity, governments could take a hands off approach and rely upon social stigmas to regulate the North American populations' fat content. As put forth by my examination of the biblical moralization of fat, the stigma of fat runs deep within our society and thus could be utilized as powerful governing tool. Rather than simply cast negative moral connotations onto the obese, stigma is an active governing tool present within society which affirms the collective values of society while excluding those who transgress from the shared moral beliefs held by greater society.

While the current regulatory process does gain much of its legitimatization from the

${ }^{296}$ Carr and Friedman, at 246. 
social stigma surrounding obesity, stigma itself may be effective enough to supplant the need for formal methods of regulatory governance. As governments are utilizing a vast array of regulatory methods to conserve financial expenditures, the money saved by leaving the governance of obesity to societal mores and not to bureaucratic regulatory practices, could be used to fund the health care initiatives to then care for the overweight population. Furthermore, rather than be forced to implant their governing strategy within the bodies of the population, American and Canadian governments could rely upon existing social pressure. It is by relying on the pressure stemming from society onto the obese to conform to a smaller standard of physical being, that rates of obesity may become mitigated without the need for formal regulation. Furthermore, the nature of obese individuals to project outside stigma onto themselves may in fact increase the effectiveness of an informal approach to the governance of obesity.

Another alternative to the current regulatory approach being undertaken by Canadian and American governments is that of medicalization. Rather than utilize the social stigma which surrounds obesity as a means of justifying the use of numerous forms of regulatory tactics, obesity the governance of obesity could be limited to medical means. As put forth by Rose, medicalization involves the creation or appropriation of a problem through the apparatus of medicine. ${ }^{297}$ It is by means of medicalization that governance of obesity would be largely restricted to the relationship between physician and patient.

While the current regulatory approach involves the expansion of governing targets by means of a moral panic and the use of the inclusive body mass index scale, limiting the governing body to medical professionals could omit the need for both sprawling ${ }^{297}$ Rose at 700. 
measures. Rather than be a matter of national importance, it is within a medical setting that the ramifications of obesity could be limited to the health of the individual. Rather than apply an often flawed universal standard of obesity measurement such as the BMI scale, an individual approach to health could be taken which calculates levels of health not based upon excess fat, but other physical factors. Furthermore, rather than relying upon a vast array of regulatory bodies to indirectly influence the decision making process of individuals to lose weight, doctors could take a more direct approach in altering the behaviour of their patients to foster weight loss.

Whereas individuals are often resistant to forms of government regulation aimed at the human body, the close nature of the doctor patient relationship provides a medium through which North Americans can be monitored and directly persuaded to alter their weight through the fulfillment of healthier life choices. Furthermore, it would be through the medicalization of obesity that government initiatives that effect non-obese consumers such the proposed fat taxes could be eliminated with the incentive to curb obesity being confined to those who are presently obese.

Another substitute to the governmentality based regulatory strategy being currently put forth to fend off obesity is an approach of non-governance. Rather than assert the governing objectives of the state within the bodies of the North American population, governments could take a hands off approach and revert to the pre-problematization of obesity when the existence of excess fat was considered a private issue. Furthermore, as levels of obesity are rising and more members of society are becoming obese instead of seeking to alter the population, government authorities could simply represent and vie for the needs of the changing population. 
As mentioned within the context of the problematization of fat, rates of obesity have increased due to recent changes in the North American lifestyle, such the rise of computer based work settings and the popularization of video gaming. It can be argued that obesity is simply a logical consequence of the rising availability of high caloric convenience foods and spending increased amounts of time in a stationary setting, be it in front of a television or computer. Therefore, the increase of the overweight population could be regarded as a new social demographic, whose interests should be represented by the elected governing power. Furthermore, in the wake of an increase in overweight American and Canadian citizens perhaps the best form of action would be to not focus on governance, but to simply foot the bill for the costs placed onto society by this new demographic. While examples do exist whereas the rights of the obese are upheld in the face of a cost effective alternative do exist, such as the Canadian transportation agency's ruling that was upheld by the Supreme Court which favoured the rights of the obese to be given a second airplane seat at no extra charge. ${ }^{298}$ However, given the commonly supposed stigmatization of obesity, held by both the obese and non-obese it is unlikely that this no governance approach to obesity would be feasible. Furthermore it is exceedingly improbable that North American governments would opt to lose money from a source they could otherwise manipulate through governance and capitalize upon monetary benefits.

As addressed within my literature review, while other sources examine the separate implications of stigma and obesity, they neglect to address the more important repercussions of governance. It is by means of utilizing an approach which synthesizes

\footnotetext{
298 "Decision No. 6-AT-A-2008" Canadian Transportation Agency, http://www.otc-cta.gc.ca/decisionruling/decision-ruling.php?type $=d \&$ no-num=6-AT-A-2008\&lang=eng. January $10^{\text {th }} 2008$.
} 
the informal stigmatizations present within society with those of formal regulation that human fat becomes a governable tool. Moreover, rather than study the topic of obesity through a strictly medical or regulatory perspective, the above approach accounts for not only the government's motivation for implementing obesity regulation, but the accompanying reasons which explain why obese and non-obese North American's are active participants in the process. As none of the previous studies account for the current regulatory climate that surrounds obesity, this study provides a much need methodology for explaining how human fat has been transformed into a widespread system of human governance. Furthermore, rather than view the regulation of obesity as a relationship that consists of the governed and the governors, the connection between the obese and the regulating government, must be observed as a interlacing of two often opposing groups to achieve the goal of obesity governance; albeit for different reasons.

As this study of obesity exclusively concerns the regulatory strategy being put forth by American and Canadian governments, a potential for future research could involve examining the governance of obesity in other parts of the world. Furthermore, by studying the governance of obesity in other countries comparisons or even further alternatives could be applied to the North American approach. While my analysis developed a theoretical framework from which to understand the current trend of obesity governance, a similar outline could be utilized to understand methods of governance behind other historically stigmatized bodily issues. Additionally, further research could be focused upon the role that informal modes of governance such as stigma in the problematization and implementation of formal laws; while exploring the relationship between the governed and the governors. 


\section{$\underline{\text { References }}$}

Albala, K., "Weight Loss in the Age of Reason" In C.E. Forth \& A. Carden-Coyne (Eds.). Cultures of the abdomen: Diet, digestion, and fat in the modern world (New York: Macmillan 2005).

Arkansas' School BMI Assessment, National Association of State Boards of Education. Vol. 12, No. 1 January 2007. http://nasbe.org/index.php/shs/80-he-projectnews/132-arkansas-school-bmi-assessment

Blain, G., "Governor Paterson proposes 'Obesity Tax,' a tax on non-diet sodas" Daily News Albany Bureau. Sunday December $14^{\text {th }} 2008$.

Bourke, J., Dismembering the Male: men's bodies, Britain and the Great War (Chicago: University Of Chicago Press, 1996).

Cahnman, W.,"The Stigma of Obesity", The sociological Quarterly (Summer 1968) Vol 9. No 3.

Campos, P., "The Legalization of Fat: Law, Science, and the Construction of a Moral Panic" (March 3, 2006). Bepress Legal Series. Working Paper.

Canadian Institute for Health Information, Obesity in Canada Identifying Policy Priorities (Ottawa: INMD publications June 2003).

Canadian Transportation Agency "Decision No. 6-AT-A-2008", http://www.otccta.gc.ca/decision-ruling/decision-ruling.php?type=d\&no-num=6-AT-A2008 \&lang=eng. January $10^{\text {th }} 2008$.

Carr, D., \& Friedman, M., "Is Obesity Stigmatizing? Body Weight, Perceived Discrimination and Psychological Well-Being in the United States" Journal of Health and Social Behavior (Sept. 2005) Vol. 46 No 3.

Carter, C., Cookie Monster: 'Me eat less cookies' Associated Press June 42005. http://www.usatoday.com/life/television/news/2005-04-07-cookie-monster_x.htm

Cawley, J., "The Impact of Obesity on Wages" (2004) The Journal of Human Resources .Vol 39. No. 2.

CBC News, "Your View: Should Airlines Charge Obese Flyers for Second Seats?" http://www.cbc.ca/news/yourview/2009/04/should_airlines_charge_obese_f_1.html , April 172009.

Cohen, S., Folk Devils and Moral Panics (London: MacGibbon and Kee, 1972). 
Cole, P., "The Moral Bases for Public Health Interventions" Epidemiology, (Jan, 1995) Vol 6. No 1.

Dayner, R., et al, "Private Enforcement: Litigation as a tool to Prevent Obesity" (2004) Journal of Public Health Policy Vol. 25 No 3/4.

Dean, M., Governmentality: Power and Rule in Modern Society (London: Sage Publications, 1999).

DeJong, W., "The Stigma of Obesity: The Consequences of Naïve Assumptions Concerning the Causes of Physical Deviance" Journal of Health and Social Behaviour (1980) Vol. 21.

Elliott, C., "Childhood Obesity and our Toxic Environment: Suggestions for Future Research" Journal of Family and Consumer Sciences Education, (2005) 22(3).

"F as in Fat: How Obesity Policies are Failing in America 2005" Trust for America's Health. August 2005, www.healthyamericans.org.

Ferraro, K., "Firm Believers? Religion, Body Weight, And Well-Being" (March 1998) Vol. 39, No. 3. Review of Religious Research.

Flegal, K.M., et al. "Excess Deaths Associated with Underweight, Overweight and Obesity" (2005) 293 JAMA.

Food and Nutrition Board: Institute of Medicine of the National Academies, "Dietary Reference Intakes for Energy, Carbohydrate, Fiber, Fat, Fatty Acids, Cholesterol, Protein, and Amino Acids (Macronutrients)." (Washington: National Academies Press, 2009).

Foucault, M., Naissance de la biopolitique: cours au College de France (1978-1979) (Paris: Gillimard \& Seuil:2001).

Foucault, M., The Foucault Reader (Harmondsworth: Penguin, 1986).

Foucault. M., The History of Sexuality an Introduction Volume 1 (New York: Random House, 1978).

George, D., Preference Pollution: How Markets Create the Desires We Dislike (University of Michigan Press: 2001).

Goffman, E., Stigma: notes on the management of spoiled identity (Englewood cliffs, N.J.: Prentice hall 1963).

Goode, E. \& Ben-Yehuda, N., Moral Panics the Social Construction of Deviance (Oxford: Blackwell Publishing, 1994). 
Gortmaker, S., "Impact of a school-based interdisciplinary intervention on Diet and physical activity among urban Primary school children: Eat well and keep moving."Archives of pediatric and adolescent medicine (1999) 153, no 9.

Gortmaker, S., "Reducing Obesity via school-based interdisciplinary Intervention among youth: Planet Health"(1999) Archives of pediatric and adolescent medicine 153, no 9.

Gostin, L., "Law as a tool to facilitate healthier lifestyles and prevent obesity"(2007) JAMA. Jan 3, 297.

Government of Canada, Childhood Obesity and the Role of the Government of Canada. 2007. Available online http://www.phac-aspc.gc.ca/chselobesity/pdf/chobesity_e.pdf

Greaney, D., "King-Size Homer". Episode Number 135. The Simpsons. Fox Television. November 51995.

Hall, S., Policing the Crisis: Mugging, the State and Law and Order (New York: Palgrave Macmillian, 1978).

Hanson, J., \& Kaysar, A., "Taking Behavioralism Seriously: Some Evidence of Market Manipulation" Harvard Law Review (1999).

Harvard Law Review "The Elephant in the Room: Evolution Behavioralism, and Counteradvertising in the Coming War Against Obesity" (Feb, 2003) Harvard Law Review, Vol 116 No. 4

Hayne, C., et al. "Regulating Environments to Reduce Obesity" Journal of Public Health Policy,(2004) Vol. 25, No. $3 / 4$.

Hayry, H., The Limits of Medical Paternalism. (Routledge: London, 1991).

Health Canada. "Canada's New Government Calls on Industry to Adopt Limits for Trans Fat". June 2007. http://www.hc-sc.gc.ca/ahc-asc/media/nrcp/2007/2007_74_e.html.

Health Canada, "Food and Nutrition: Trans fat" (2009) http://www.hc-sc.gc.ca/fnan/nutrition/gras-trans-fats/index-eng.php.

Health Canada, "Questions and Answers - Food Fortification Proposed Policy" June 2007. http://www.hc-sc.gc.ca/fn-an/nutrition/vitamin/faqs-eng.php Hunt, A., "Moral Panic and Moral Language in the Media"(1997) Vol. 48, Issue 4. The British Journal of Sociology. 
Holm, S., "Obesity Interventions and Ethics" Obesity Reviews (2007) 8. (Suppl.1).

International Obesity Task Force, "Global strategies to prevent Childhood obesity: Forging a societal plan that works" A discussions paper prepared for the Global Prevention Alliance McGill Integrative Health Challenge October 26-27 2006.

Jones, E., \& Davis, K.E., "From acts to dispositions: the attribution process in person perception" in Leonard Berkowitz (ed.) Advances in Experimental Social Psychology, Vol. 2 New York: Academic Press.

Kalisch, B., "The Stigma of Obesity" The American Journal of Nursing (June 1972) vol. 72 No. 6 at 1124-1127.

Kim, K.H., "Religion and Body Weight" (2003) International Journal of Obesity 27.

Langer, E.J., et al, "Stigma, Staring, and Discomfort: A novel stimulus and hypothesis" (1976) Journal of Experimental Psychology, 12.

Lemert, M., Social Pathology (New York: McGraw Hill, 1951).

Lemke, T., "The birth of bio-politics: Michael Foucault's lectures at the College de France on neo-liberal governmentality" (2001) v.30, i.2, Economy and Society.

Lindsay, A., "The role of parents in preventing child obesity" (Spring 2006) Future of Children vol. 16 No. 1.

Link, B., \& Phelan., J. "Conceptualizing Stigma" (2001) Annual Review of Sociology 27.

Locke, J., An Essay Concerning Human Understanding (Oxford: Clarendon Press, 1984).

Maddox. G., "Overweight and Social Deviance and Disability" Journal of Health and Social Behaviour. (Dec 1968) Vol. 9.

Manis, J., "The concept of social problems: vox populi and sociological analysis" (1974) Vol. 21 Winter. Social Problems.

McKinnon, A., British Columbia Ministry of Healthy Living and Sport "Province restricts trans fat in B.C" Press release. (March 7, 2009). $\mathrm{http} / / / \mathrm{www} 2 . n e w s . g o v . b c . c a / n e w s \_r e l e a s e s \_2005-2009 / 2009 H L S 0013-$ 000315.htm.

Miles, M., "Religion and Food: The Case of Eating Disorders" (1995) Vol. 63, No.1. Autumn 1995 Journal of the American Academy of Religion.

O’Malley, P., Crime and the Risk Society (Aldershot: Ashgate, 1998). 
Pickering, W.S.F., ed. Durkheim on Religion: A Selection of Readings with Bibliographies. (London: Routledge \& Kegan Paul, 1975).

Phillips, S.,"Measuring Obesity in Young Children" (Dec. 2004) Canadian Public Policy. Vol 30 No. 4.

Poole, R., “On Being a Person” (1996) 74 , Australasian Journal of Philosophy .

Puhl, P., \& Brownell, K., "Bias, Discrimination, and Obesity" (2001) 9 Obesity Res.

Raczynski, J., "Arkansas Act 1220 of 2003 to Reduce Childhood Obesity: Its Implementation and Impact on Child and Adolescent Body Mass Index" (2009) Journal of Public Health Policy, Volume 30, Supplement 1, 2009 .

Richardson. S., "Cultural Uniformity and Reaction to Physical Disability" Am. Social rev (1961).

Rivera, J., "Pediatricians' Child Obesity Policy Statement Mirrors Ortiz Bill. National Group Calls for More Community Programs" http://assembly.state.ny.us/comm/Food/20030805/ August 5, 2003, Accessed March 122009.

Rose, N., \& Valverde, M., “Governed By Law?” (1998) Social \& Legal Studies, Vol. 7.

Rose, N., "Beyond Medicine" (2007) Vol. 369. The Lancet Journal

Rose. N., Powers of Freedom: reframing political thought. (Cambridge: Cambridge University Press 1999).

Saguy, A., \& Almeling, R.,"Fat Panic! The "Obesity Epidemic as Moral Panic" Paper presented at the annual meeting of the American Sociological Association, Marriott Hotel, Loews Philadelphia Hotel, Philadelphia, PA, Aug 12, 2005 Accessed March 23 2009. http://www.allacademic.com/meta/p22928_index.html.

Saguy, A. \& Riley, K., "Framing Contests Over Obesity" (2005) 30 Journal of Health Politics Policy \& Law.

Spector, M. \& Kitsuse, J., "Social Problems: a re-formulation." (1973) Vol. 21 Fall. Social Problems.

Stearns, P., Fat in America. In C.E. Forth \& A. Carden-Coyne (Eds.). Cultures of the abdomen: Diet, digestion, and fat in the modern world (New York: Macmillan 2005).

US Weekly, Issue 611. October 30, 2006. 
US Weekly, Issue 731. February 16, 2009.

Wallwork, E., "Durkheim's Early Sociology of Religion" (Autumn, 1985), Sociological Analysis, Vol. 46, No. 3.

Wright, B., "Surgeon general to cops: put down the donuts" http://www.cnn.com/2003/HEALTH/02/28/obesity.police, March 2 2003, Accessed April 22009.

Ver Ploeg, M., "WIC and the Battle Against Childhood Overweight Economic Brief" (2009) No. (EB-13) United States Department of Agriculture, Economic Research Service.

Zweiniger-Bargielowska, I.,"The Culture of the Abdomen: Obesity and Reducing in Britain, circa 1900-1939” (2005) Journal of British Studies.

\section{Court Cases}

Committee on Children's Television, Inc. v. General Foods Corp. (1983) 35 Cal.3d 197, 209- 210, 197 Cal.Rptr. 783, 673 P.2d 660.

New York State Restaurant Association (NYSRA) v. New York Department of Health, http://www.citizen.org/litigation/forms/cases/CaseDetails.cfm?cID=420

Pelman v. McDonald's Corp., 237 F.Supp. 512 (S.D.N.Y. 2003).

\section{Legislation}

California House Bill SB 1420 2007-2008 Session.

Commonsense Consumption Act of 2005, H.R. 554, $109^{\mathrm{TH}}$ Cong.

Food, Drug and Cosmetic Act, 21 U.S.C. 321(n), 343(a) (1994).

Junk Food and Soda Free Schools Act. City of New York City Council. Int. No 306.

Mississippi Legislature 2008 Regular Session House Bill 282.

Required physical activity in schools Act 2004, Louisiana Legislature.,No. 734, §1, eff. July 6, 2004. 